\title{
Efficient Removal of Cu(II), Zn(II), and Cd(II) from Aqueous Solutions by a Mineral-Rich Biochar Derived from a Spent Mushroom (Agaricus bisporus) Substrate
}

\author{
Guosheng Zhang ${ }^{1}$, Na Liu ${ }^{1}$, Yuan Luo ${ }^{1}$, Haibo Zhang ${ }^{1}$, Long Su ${ }^{1}$, Kokyo Oh ${ }^{2}$ and Hongyan Cheng ${ }^{1, *}$ \\ 1 College of Resources and Environment, Shanxi Agricultural University, Jinzhong 030801, China; \\ zhanggs@stu.sxau.edu.cn (G.Z.); liuna@sxau.edu.cn (N.L.); luoyuan@sxau.edu.cn (Y.L.); \\ zhanghb@sxau.edu.cn (H.Z.); sulong@stu.sxau.edu.cn (L.S.) \\ 2 Center for Environmental Science in Saitama, Kazo City, Saitama 347-0115, Japan; peace6728@yahoo.co.jp \\ * Correspondence: sxauchenghy@sxau.edu.cn
}

Citation: Zhang, G.; Liu, N.; Luo, Y.; Zhang, H.; Su, L.; Oh, K.; Cheng, H. Efficient Removal of $\mathrm{Cu}(\mathrm{II}), \mathrm{Zn}(\mathrm{II})$, and Cd(II) from Aqueous Solutions by a Mineral-Rich Biochar Derived from a Spent Mushroom (Agaricus bisporus) Substrate. Materials 2021, 14, 35. https://dx.doi.org/

10.3390/ma14010035

Received: 2 December 2020 Accepted: 21 December 2020 Published: 23 December 2020

Publisher's Note: MDPI stays neutral with regard to jurisdictional claims in published maps and institutional affiliations.

Copyright: () 2020 by the authors. Licensee MDPI, Basel, Switzerland. This article is an open access article distributed under the terms and conditions of the Creative Commons Attribution (CC BY) license (https: / / creativecommons.org/ licenses/by/4.0/).

\begin{abstract}
This study evaluated the novel application of a mineral-rich biochar derived from a spent Agaricus bisporus substrate (SAS). Biochars with various pyrolysis temperatures $\left(350-750{ }^{\circ} \mathrm{C}\right)$ were used to remove $\mathrm{Cu}(\mathrm{II}), \mathrm{Zn}(\mathrm{II})$, and $\mathrm{Cd}(\mathrm{II})$ from aqueous solutions. The adsorption characteristics and removal mechanisms of the biochars were investigated. The adsorption kinetics and isotherm data were fitted well by pseudo-second-order and Freundlich models. The Langmuir maximum removal capacity $\left(Q_{\max }\right)$ values of $\mathrm{Cu}(\mathrm{II}), \mathrm{Zn}(\mathrm{II})$, and $\mathrm{Cd}(\mathrm{II})$ were ordered as SAS750 > SAS350 > SAS550, and the $Q_{\max }$ values of SAS750 were $68.1,55.2$, and $64.8 \mathrm{mg} \cdot \mathrm{g}^{-1}$, respectively. Overall, the removal mechanisms of biochar at a low production temperature $\left(350^{\circ} \mathrm{C}\right)$ to $\mathrm{Cu}(\mathrm{II}), \mathrm{Zn}(\mathrm{II})$, and $\mathrm{Cd}(\mathrm{II})$ were mainly via ion exchange $(54.0,56.0$, and $43.0 \%)$, and at a moderate production temperature $\left(550{ }^{\circ} \mathrm{C}\right)$, removal mechanisms were mainly via coordination with $\pi$ electrons $(38.3,45.9$, and 55.0\%), while mineral precipitation $(65.2,44.4$, and $76.3 \%$, respectively) was the dominant mechanism at a high produced temperature $\left(750{ }^{\circ} \mathrm{C}\right)$. The variation of the mutual effect of minerals and heavy metals was the predominant factor in the sorption mechanism of mineral precipitation and ion exchange. The results demonstrated that spent Agaricus bisporus substrate biochar is a potential candidate for the efficient removal of heavy metals, which provides a utilization route for spent mushroom substrates.
\end{abstract}

Keywords: spent mushroom substrate; biochar; pyrolysis temperature; mineral; heavy metal; sorption characteristic; mechanisms

\section{Introduction}

Edible fungi are organic, green, and healthy foods. As one of the most promising food industries, the edible fungus industry has developed rapidly in recent decades. However, approximately $5 \mathrm{~kg}$ of spent mushroom substrate is generated during the production process of $1 \mathrm{~kg}$ of edible fungi [1,2]. In 2018, approximately 70 million tons of edible fungi were produced in China; hence, a large amount (approximately 350 million tons) of spent mushroom substrate had to be treated and utilized. Various methods have been proposed for the reuse of spent mushroom substrates, such as conventional treatment methods, e.g., as compost [3,4] or feed [5]; however, these methods are only suitable for treating small amounts of substrate. Most spent mushroom substrates are not effectively disposed of and are randomly stacked or burned in open air [6]. Therefore, the development of an economical and environmentally friendly treatment method for spent mushroom substrates is necessary.

Biochar is a carbon-rich solid material that is produced from biomass in an oxygenlimited atmosphere and can adsorb a variety of pollutants [7], especially in aqueous solutions that are polluted by heavy metals [8,9]. A variety of agricultural by-products have been converted into biochar and used as environmental adsorbents to remove heavy 
metals. Previous studies have reported that biochars derived from feedstock materials such as peanut shells $[10,11]$, wood chips $[12,13]$, corn straw [14,15], and rice straw $[16,17]$ can remove $\mathrm{Cu}(\mathrm{II}), \mathrm{Zn}(\mathrm{II})$, and $\mathrm{Cd}(\mathrm{II})$ effectively from aqueous solutions. Recent reports have highlighted the indispensable role of mineral components in biochar sorption [18,19], and mineral-rich biochar has excellent removal ability for heavy metals. Biochar with a high mineral content can remove heavy metals through complex mechanisms, which may involve (1) mineral precipitation, (2) cation exchange, (3) complexation of surface functional groups, and (4) interaction of $\pi$ electrons with heavy metals [20-22]. In summary, mineral-rich biochar may be an effective material for removing a variety of heavy metals from water and is more economical than other materials.

Mineral-rich biochar can be produced from spent Agaricus bisporus substrates. As a delicious mushroom, Agaricus bisporus is grown worldwide and loved by consumers. In the cultivation of Agaricus bisporus, in addition to composting and fermentation with chicken manure and rice straw, calcium-containing minerals are applied as nutrients and in surface-covering soil. These processes form a culture medium that is suitable for mycelial growth [5], which renders the spent Agaricus bisporus substrate rich in minerals and potentially suitable for the preparation of biochar. Few reports have been published on the production of biochar from spent Agaricus bisporus substrates. The properties of the prepared biochar, its performance, and its mechanism of adsorbing heavy metals have yet to be elucidated. Meanwhile, the contribution to the biochar removal mechanism of heavy metals is attributed to the constraints of the biochar source and the pyrolysis temperature [23]. The properties of biochar differ according to the pyrolysis temperature [24], thereby resulting in differences in importance among the mechanisms in the sorption process. Few current studies have clarified the relationship between the differences in physicochemical properties among biochars that were synthesized at different pyrolysis temperatures and the relative contributions of various mechanisms to the sorption of heavy metals. In addition, excessive heavy metals, namely, copper $(\mathrm{Cu})$ and zinc $(\mathrm{Zn})$, are present in livestock and poultry breeding wastewater due to feeding addition, and highly toxic cadmium (Cd) is also considered a potential environmental threat.

In this study, biochars were prepared from a spent Agaricus bisporus substrate at various pyrolysis temperatures $\left(350-750^{\circ} \mathrm{C}\right)$, and their physical and chemical properties were characterized via various techniques (1) to determine the ability of biochar to adsorb $\mathrm{Cu}$ (II), $\mathrm{Zn}(\mathrm{II})$, and Cd(II) in aqueous solutions; (2) to determine the effects of the pyrolysis temperature on the sorption capacity of the biochar; and (3) to qualitatively and quantitatively investigate the mechanism via which the biochar removes $\mathrm{Cu}(\mathrm{II}), \mathrm{Zn}(\mathrm{II})$ and $\mathrm{Cd}(\mathrm{II})$ from aqueous solutions.

\section{Materials and Methods}

\subsection{Biochar Preparation}

The feedstock of a spent Agaricus bisporus substrate (SAS) was provided by the Edible Fungus Center of Shanxi Agricultural University, Taigu County, China. The fresh feedstock was placed in a ventilated environment to air-dry for a week, and small stones were manually removed at this time. After air-drying, the SAS was crushed to a particle size of $>0.5 \mathrm{~cm}$ using a crusher and dried at $60^{\circ} \mathrm{C}$ until it reached a constant weight. Approximately $55-60 \mathrm{~g}$ of the dried SAS was placed in a porcelain crucible and compacted (with a volume of $100 \mathrm{~mL}$ ), and the crucible was put in a muffle furnace with a limited oxygen environment. Then, the temperature was increased at a rate of $20^{\circ} \mathrm{C} \cdot \mathrm{min}^{-1}$ to the specified temperature $\left(350,450,550,650\right.$, and $\left.750^{\circ} \mathrm{C}\right)$, and the sample was pyrolyzed at the peak temperature for $3 \mathrm{~h}$. The spent Agaricus bisporus substrate biochars (SASCs) (the remaining solid substances after pyrolysis) were labeled as SAS350, SAS450, SAS550, SAS650, and SAS750 according to the pyrolysis temperature. All SASCs were ground to particle sizes of $>0.15 \mathrm{~mm}$ prior to use. Demineralized biochar samples were obtained by eluting the biochar with $1 \mathrm{~mol} \cdot \mathrm{L}^{-1}$ $\mathrm{HCl}$ and washed with distilled water until the $\mathrm{pH}$ of the solution no longer changed. 


\subsection{Characterization of SASCs That Were Obtained at Various Pyrolysis Temperatures}

The $\mathrm{pH}$ values of all samples were determined using a $\mathrm{pH}$ meter (Lei-ci PHS-3Ct, Shanghai, China) with a water/sample ratio of 10:1 after shaking for $30 \mathrm{~min}$. The concentrations of elements (C, N, H, and S) were determined via elemental analyses (Vario Macrocube Elementar, Langenselbold, Germany). The surface areas were determined from Brunauer-Emmett-Teller (BET) isotherms with $\mathrm{N}_{2}$ sorption at $77 \mathrm{~K}$ that were obtained using a surface area analyzer (ASAP2020, Micromeritics, Norcross, GA, USA). The ash contents of the SASCs were determined by heating the samples at $700{ }^{\circ} \mathrm{C}$ for $2 \mathrm{~h}$, and the metal contents were determined via inductively coupled plasma optical emission spectrometer (ICP-OES, Optima 5300 DV, PerkinElmer, Waltham, MA, USA). The morphologies and elemental species of the biochars were analyzed using scanning electron microscopy and energy dispersive X-ray (SEM/EDS, JEOL JSM-6510, Tokyo, Japan). The surface functional groups in the biochars were identified via Fourier Transform Infrared Spectroscopy (FTIR, Tensor 27 Bruker Germany) spectrometer using the $\mathrm{KBr}$ tablet method in the $4000-400 \mathrm{~cm}^{-1}$ wavelength range. The surface mineral compositions were determined via $\mathrm{X}$-ray diffraction (XRD) (D8 Advance, Bruker, Germany).

\subsection{Batch Sorption Experiments}

All sorption experiments used $0.01 \mathrm{~mol} \cdot \mathrm{L}^{-1} \mathrm{NaNO}_{3}$ as the background electrolyte, and a $0.1 \mathrm{~mol} \cdot \mathrm{L}^{-1} \mathrm{HNO}_{3}$ or $\mathrm{NaOH}$ solution was used to adjust the initial $\mathrm{pH}$ value of the required solution to $5.0 \pm 0.05$ (except for experiments with different initial $\mathrm{pH}$ values). Single-solute sorption experiments were conducted by adding $30 \mathrm{mg}$ of SASC $\left(w / v, 1 \mathrm{~g} \cdot \mathrm{L}^{-1}\right)$ to $30 \mathrm{~mL}$ of a Cd(II) or $\mathrm{Cu}$ (II) or $\mathrm{Zn}$ (II) solution at $25^{\circ} \mathrm{C}$ and $200 \mathrm{rpm}$. The initial $\mathrm{pH}$ of the solution was adjusted to $2.0-6.0$ to determine the effects of various initial $\mathrm{pH}$ values on the sorption of heavy metals by the biochars.

To investigate the sorption kinetics, the initial concentration of the solution was $100 \mathrm{mg} \cdot \mathrm{L}^{-1}$, and samples were obtained at various time intervals that ranged between 0.17 and $48 \mathrm{~h}$. To obtain the sorption isotherm, the concentration of the initial solution was $0-250 \mathrm{mg} \cdot \mathrm{L}^{-1}$, and it was shaken for $24 \mathrm{~h}$. According to the kinetic experiment, when the adsorption reached $24 \mathrm{~h}$, the adsorption capacity did not change apparently, and the adsorption basically reached equilibrium. After oscillation, the adsorptive solution was collected and filtered with a 0.22-micron-aperture filter. The amount of remnant heavy metal ions in the filtrates was determined via ICP-OES. All adsorption experiments were performed in triplicate, and the average value was taken as the result, while the value for a blank without an added sample was used as a correction to eliminate possible errors. For the FTIR, XRD, SEM, and EDS analyses, $100 \mathrm{~mL}$ of a heavy metal solution with a concentration of $1000 \mathrm{mg} \cdot \mathrm{L}^{-1}$ was added to $1 \mathrm{~g}$ of SASC at pH $5.0 \pm 0.05$ to prepare a biochar that was loaded with $\mathrm{Cu}(\mathrm{II}), \mathrm{Zn}(\mathrm{II})$, or $\mathrm{Cd}(\mathrm{II})$.

\subsection{Contribution of Each Mechanism to the Biochar Sorption}

According to the calculation method of Cui [21], the sorption process of heavy metal ions by the biochar could be attributed to four mechanisms: (1) exchange with cations $\left(\mathrm{Q}_{\mathrm{ce}}\right)$, (2) precipitation with minerals $\left(\mathrm{Q}_{\mathrm{cp}}\right)$, (3) complexation with oxygen functional groups (OFGs) $\left(\mathrm{Q}_{\mathrm{co}}\right)$, and (4) coordination with $\pi$ electrons $\left(\mathrm{Q}_{\mathrm{c} \pi}\right)$. Other possible sorption mechanisms were not considered in the experiment due to their low contributions.

(1) The contribution of cation exchange $\left(\mathrm{K}^{+}, \mathrm{Ca}^{2+}, \mathrm{Na}^{+}\right.$and $\left.\mathrm{Mg}^{2+}\right)$ depends on the difference in the concentrations of exchangeable cations in the solution before and after biochar sorption, which could be calculated from the difference in the amounts of exchangeable cations that are released between normal sorption and sorption without heavy metals.

$$
\mathrm{Q}_{\mathrm{ce}}=\mathrm{Q}_{\mathrm{K}}+\mathrm{Q}_{\mathrm{Ca}}+\mathrm{Q}_{\mathrm{Na}}+\mathrm{Q}_{\mathrm{Mg}}
$$

where $\mathrm{Q}_{\mathrm{K}}, \mathrm{Q}_{\mathrm{Ca}}, \mathrm{Q}_{\mathrm{Na}}$, and $\mathrm{Q}_{\mathrm{Mg}}$ are the net values of $\mathrm{K}^{+}, \mathrm{Ca}^{2+}, \mathrm{Na}^{+}$and $\mathrm{Mg}^{2+}$, respectively, in $\mathrm{mg} \cdot \mathrm{g}^{-1}$ that are released into the solution by the SASC sorption process. 
(2) Most minerals in biochar are removed after acid leaching, while the oxygencontaining functional groups (OFGs) are unchanged; hence, the contributions of mineral precipitation $\left(\mathrm{Q}_{\mathrm{cp}}\right)$ and ion exchange $\left(\mathrm{Q}_{\mathrm{ce}}\right)$ can be calculated from the reduction in biochar sorption before versus after acid leaching.

$$
\mathrm{Q}_{\mathrm{cp}}=\mathrm{Q}_{\mathrm{t}}-\mathrm{Q}_{\mathrm{a}} \times \mathrm{y}-\mathrm{Q}_{\mathrm{ce}}
$$

where $\mathrm{Q}_{\mathrm{t}}\left(\mathrm{mg} \cdot \mathrm{g}^{-1}\right)$ is the total sorption of SASC, $\mathrm{Q}_{\mathrm{a}}$ is the amount of sorption on acidwashed biochar, and $\mathrm{y}$ is the yield of acid-washed biochar.

(3) The following chemical reaction formula explains the drop in the solution $\mathrm{pH}$ after acid-washed biochar sorption:

$$
\begin{gathered}
-\mathrm{COOH}+\mathrm{Cu}^{2+}+\mathrm{H}_{2} \mathrm{O} \rightarrow-\mathrm{COOCu}^{+}+\mathrm{H}_{3} \mathrm{O}^{+} \\
-\mathrm{OH}+\mathrm{Cu}^{2+}+\mathrm{H}_{2} \mathrm{O} \rightarrow-\mathrm{OCu}^{+}+\mathrm{H}_{3} \mathrm{O}^{+} .
\end{gathered}
$$

Therefore, the contribution of OFGs could be calculated from the drop in the solution $\mathrm{pH}$ value.

The sorption capacity of the acid-washed biochar is the result of the interactions between $\pi$ electrons and OFGs. Therefore, the contribution of $\pi$ electrons to adsorption could be calculated from the difference between the adsorptions of the acid-washed biochar and OFGs.

$$
\mathrm{Q}_{\mathrm{c} \pi}=\mathrm{Q}_{\mathrm{a}} \times \mathrm{y}-\mathrm{Q}_{\mathrm{co}}
$$

The contribution rates of these mechanisms in the sorption process are expressed as $\mathrm{Q}_{\mathrm{cp}} / \mathrm{Q}_{\mathrm{t}}, \mathrm{Q}_{\mathrm{co}} / \mathrm{Qt}, \mathrm{Q}_{\mathrm{ce}} / \mathrm{Q}_{\mathrm{t}}, \mathrm{Q}_{\mathrm{c} \pi} / \mathrm{Q}_{\mathrm{t}}$.

\section{Results}

\subsection{Characteristics of Biochar}

The composition of the feedstock has a decisive influence on the characteristics of the biochar. Compared with other biochar feedstocks, spent Agaricus bisporus substrates are complex mixtures that are derived from edible fungal cultivation. In the process of cultivation, straw, chicken manure, and gypsum are used as nutrients, and peat soil is applied as a cover to provide a growth environment. The yield and ash content of biochars from spent Agaricus bisporus substrates exceeded those from common feedstock (e.g., wheat straw [25], halophyte [26], and corn straw [14]).

The high mineral content results in a very high yield of SASC, which is still $64.6 \%$ even at the highest pyrolysis temperature, and such a high yield can be attributed to the higher ash content in the biochar. The ash content reached a maximum of $82.1 \%$ at $750{ }^{\circ} \mathrm{C}$, which supported the presence of large amounts of inorganic minerals in spent Agaricus bisporus-derived biochars.

The pyrolysis temperature is another key factor that affects the properties of a biochar [27]. The properties of SASC are summarized in Table 1. Element analyses showed that the contents of $\mathrm{C}, \mathrm{H}, \mathrm{O}$, and $\mathrm{N}$ decreased continuously with the increase of the pyrolysis temperature. The contents of $\mathrm{C}, \mathrm{H}, \mathrm{N}$ and $\mathrm{O}$ are $17.5 \%, 1.3 \%, 13.5 \%$, and $1.5 \%$, respectively, after pyrolysis at $350{ }^{\circ} \mathrm{C}$, and they decline rapidly to $12.2 \%, 0.3 \%, 4.65 \%$, and $0.85 \%$, respectively, at $750{ }^{\circ} \mathrm{C}$. The ratios $\mathrm{H} / \mathrm{C}$ and $\mathrm{O} / \mathrm{C}$ also decrease with the pyrolysis temperature. These results demonstrate that higher-temperature biochar had stronger aromaticity and polarity, which was supported by the subsequent FTIR results. During pyrolysis, many carbon-containing substances will be converted into gaseous hydrocarbon compounds and aromatic hydrocarbons of tar [28], and the gradual loss of volatile substances will remove many surface functional group elements $(\mathrm{H}, \mathrm{O}$ and $\mathrm{N})$. 
Table 1. Physicochemical properties of biochars at different pyrolysis temperature.

\begin{tabular}{|c|c|c|c|c|c|c|c|c|c|c|c|c|c|c|c|}
\hline \multirow{2}{*}{ Material } & \multirow{2}{*}{ Yield (\%) } & \multirow{2}{*}{$\mathrm{pH}$} & \multirow{2}{*}{ Ash (\%) } & \multicolumn{8}{|c|}{ Elemental Contents (\%) } & \multirow{2}{*}{$\mathrm{H} / \mathrm{C}$} & \multirow{2}{*}{$\mathrm{O} / \mathrm{C}$} & \multirow{2}{*}{$\begin{array}{c}\text { BET } \\
\left(\mathrm{m}^{2} \mathrm{~g}^{-1}\right)\end{array}$} & \multirow{2}{*}{$\begin{array}{c}\text { Total Pore } \\
\text { Volume } \\
\left(\mathrm{cm}^{3} \mathrm{~g}^{-1}\right)\end{array}$} \\
\hline & & & & $\mathrm{C}$ & $\mathbf{H}$ & $\mathrm{O}$ & $\mathbf{N}$ & $\mathrm{Ca}$ & $\mathrm{Mg}$ & $\mathbf{K}$ & $\mathrm{Na}$ & & & & \\
\hline SAS & - & 6.87 & 53.15 & 19.03 & 2.33 & 23.82 & 1.67 & 5.13 & 1.48 & 0.60 & 0.35 & 0.12 & 1.25 & 24.13 & 0.029 \\
\hline SAS350 & 78.96 & 8.83 & 66.50 & 17.53 & 1.32 & 13.49 & 1.48 & 6.45 & 1.84 & 0.64 & 0.39 & 0.08 & 0.77 & 36.20 & 0.045 \\
\hline SAS450 & 73.73 & 9.37 & 71.76 & 15.91 & 0.82 & 11.73 & 1.20 & 7.13 & 1.97 & 0.68 & 0.42 & 0.05 & 0.78 & 48.74 & 0.065 \\
\hline SAS550 & 70.98 & 9.51 & 74.08 & 15.22 & 0.54 & 9.87 & 1.06 & 7.30 & 2.11 & 0.69 & 0.43 & 0.04 & 0.65 & 64.19 & 0.110 \\
\hline SAS650 & 68.13 & 11.38 & 77.23 & 14.53 & 0.37 & 7.87 & 0.88 & 7.45 & 2.21 & 0.70 & 0.44 & 0.03 & 0.54 & 101.39 & 0.156 \\
\hline SAS750 & 64.60 & 11.82 & 82.12 & 12.17 & 0.26 & 4.65 & 0.85 & 7.77 & 2.41 & 0.76 & 0.45 & 0.02 & 0.38 & 37.08 & 0.091 \\
\hline
\end{tabular}

Mineral element analyses of ICP showed that SASC included calcium (Ca), magnesium $(\mathrm{Mg})$, potassium $(\mathrm{K})$, and sodium $(\mathrm{Na})$ (Table 1, Table S1), which were controlled mainly by the production temperature. The total content of $\mathrm{Ca}, \mathrm{Mg}, \mathrm{K}$, and $\mathrm{Na}$ increased from $10.41 \%$ to $11.39 \%$ as the production temperature was increased from 350 to $750{ }^{\circ} \mathrm{C}$. During pyrolysis, these inorganic minerals were not easily volatilized [29] and were retained and enriched in the biochars, while organic substances (such as hemicellulose, lignin and cellulose $\left(220-400{ }^{\circ} \mathrm{C}\right)$ and lignin $\left.\left(\sim 500^{\circ} \mathrm{C}\right)[30]\right)$ were gradually volatilized and lost, thereby resulting in an increase in the mineral element content in the biochars with increasing temperature.

Minerals are also key factors that affect the acidity or alkalinity of biochars. When not pyrolyzed, the $\mathrm{pH}$ of the raw material of SASC was 6.87 , which was slightly acidic. As the pyrolysis temperature was increased from 350 to $750{ }^{\circ} \mathrm{C}$, the $\mathrm{pH}$ of the biochar increased from 8.83 to 11.82. The alkaline earth metals ( $\mathrm{Ca}$ and $\mathrm{Mg}$ ) in biochars are converted into carbonate forms during pyrolysis [31] (such as $\mathrm{CaMg}\left(\mathrm{CO}_{3}\right)_{2}$ and $\mathrm{CaCO}_{3}$ ), which render the $\mathrm{pH}$ alkaline and gradually increase it. Meanwhile, SASC had a higher Ca content (5.13 7.77\%); hence, more alkaline minerals can be released to cause the alkaline elevation of SASC.

The specific surface area and pore volume of the biochars varied substantially with the pyrolysis temperature. Due to the formation of micropore structures in the biochars during pyrolysis, the specific surface area and porosity of the biochars increased significantly with the pyrolysis temperature [32]. As the temperature was increased from 350 to $650{ }^{\circ} \mathrm{C}$, the total pore volume of the biochars increased from 0.045 to $0.156 \mathrm{~cm}^{3} \cdot \mathrm{g}^{-1}$, and the surface area increased from 36.20 to $101.39 \mathrm{~m}^{2} \cdot \mathrm{g}^{-1}$. However, when the temperature was $750{ }^{\circ} \mathrm{C}$, the pore volume and surface area decreased to 0.091 and $37.08 \mathrm{~m}^{2} \cdot \mathrm{g}^{-1}$, respectively. The surface area of SAS750 is lower than that of the common straw biochar [33,34]. The pores of the biochar were blocked by excessive ash [35], which decreased the specific surface area and pore volume. In addition, the pore structure of the biochar collapsed at high pyrolysis temperatures [36] $\left(>700^{\circ} \mathrm{C}\right)$, which further reduced the surface area of SAS750. SEM images (Figure S1) show that the surface of the biochar was rough and contained complex networks and porous structures, which further supported the lower specific surface area of SASC. These structures became more complex and disordered as the pyrolysis temperature was increased.

\subsection{Effect of the Initial $\mathrm{pH}$ on the Sorption Performance}

The $\mathrm{pH}$ of the solution is an important factor that affects the sorption performance. It affects the forms of the ions and the protonation or deprotonation state of the biochar [37]. To explore the influence of the $\mathrm{pH}$ on the sorption of $\mathrm{Cu}(\mathrm{II}), \mathrm{Zn}(\mathrm{II})$, and $\mathrm{Cd}(\mathrm{II})$ by SASC, a range of initial $\mathrm{pH}$ values from 2.0 to 6.0 was selected for sorption experiments.

The results are presented in Figure 1. The sorption capacity of each biochar for heavy metals increased gradually with the initial $\mathrm{pH}$ value of the solution. When the $\mathrm{pH}$ value of the solution was low $(\mathrm{pH}=2.0)$, a large amount of $\mathrm{H}^{+}$was present in the solution, and the biochar was protonated and electrostatically repulsed with positively charged 
heavy metal ions. Simultaneously, the biochar released many cations (such as $\mathrm{Ca}^{2+}, \mathrm{Mg}^{2+}$, and $\mathrm{K}^{+}$) in the low $\mathrm{pH}$ solution (e.g., $\mathrm{Zn}$ (II) adsorption, Figure S2), which competed with heavy metals for sorption sites and, thus, reduced the adsorption capacity [38]. As the $\mathrm{pH}$ value was increased to 3.0, the $\mathrm{H}^{+}$content in the solution decreased, and the biochar was deprotonated. The unfavorable conditions that are described above for biochar sorption weakened; consequently, the adsorption capacity substantially increased.

After sorption, the $\mathrm{pH}$ value of the solution showed an upward trend compared with the initial value, which was attributed to the alkalinity of the biochar: the stronger the alkalinity of the biochar, the larger the $\mathrm{pH}$ increase (Figure 2a-c). However, for a blank without heavy metals (with the same volume of $\mathrm{NaNO}_{3}$ solution), the $\mathrm{pH}$ value of the solution after shaking exceeded that of the solution with heavy metals. Thus, the interaction of biochar with heavy metals reduced the $\mathrm{pH}$ value of the solution, which is consistent with the results of Wang et al. [39]. When metal ions are complexed with functional groups in the biochar, $\mathrm{H}^{+}$will be released in the solution, which will reduce the $\mathrm{pH}$ value of the solution after sorption; this will also be reflected in the sorption performance of the acid-washed biochar. In addition, the decrease in the $\mathrm{pH}$ value after sorption may also be due to the formation of precipitates with alkaline ions $\left(\mathrm{CO}_{3}{ }^{2-}\right)$ during the sorption process [21]. With increasing pyrolysis temperature, the ash (inorganic component) content of the biochar increased gradually; however, the amounts of adsorbed $\mathrm{Cu}(\mathrm{II}), \mathrm{Cd}(\mathrm{II})$ and $\mathrm{Zn}$ (II) initially decreased and subsequently increased (SAS750 > SAS350 > SAS550) (Figure 2e).

Compared with SAS550, SAS750 has a higher $\mathrm{pH}$, ash content, mineral content, and aromaticity and is more suitable for precipitation and cation exchange, while SAS350 contains more abundant oxygen-containing functional groups and is more conducive to oxygen functional group complexation. Therefore, SAS350, SAS550, and SAS750 are selected as representatives for the next kinetic and isothermal sorption experiments.

\subsection{Sorption Kinetics and Isotherms}

The results of the sorption amounts of the SASCs on $\mathrm{Cu}(\mathrm{II}), \mathrm{Zn}(\mathrm{II})$, and $\mathrm{Cd}(\mathrm{II})$ as functions of the sorption time are presented in Figure 3. With increasing sorption time, the sorption capacities of the SASCs gradually increased until equilibrium. At the initial sorption time $(0-4 \mathrm{~h})$, all three SASCs showed rapid sorption. As the sorption time progressed, the solute difference of the solution decreased, the remaining sorption sites on the SASCs gradually became saturated, with little change in the sorption capacity, and the sorption reached equilibrium. Although SAS750 exhibited the best sorption performance for each heavy metal, it exhibited a lower sorption rate and did not reach equilibrium until nearly $24 \mathrm{~h}$, which may be attributed to differences in the sorption mechanisms. The sorption rates differ among the sorption mechanisms. According to the result of LU H [40], the interactions between oxygen-containing functional groups and heavy metal ions in biochars are extremely rapid, and equilibrium can usually be reached in a short time. During the sorption process, anions that are released from biochars (e.g., $\mathrm{CO}_{3}{ }^{2-}, \mathrm{SO}_{4}{ }^{2-}$, and $\mathrm{OH}^{-}$) can precipitate with heavy metals, while the rate of mineral precipitation is affected by the release of anions [41]. Biochars under high-temperature pyrolysis have few oxygen-containing functional groups and high mineral content, which is more conducive to the removal of heavy metals through precipitation mechanisms; thus, the sorption rate is strongly affected by minerals. 

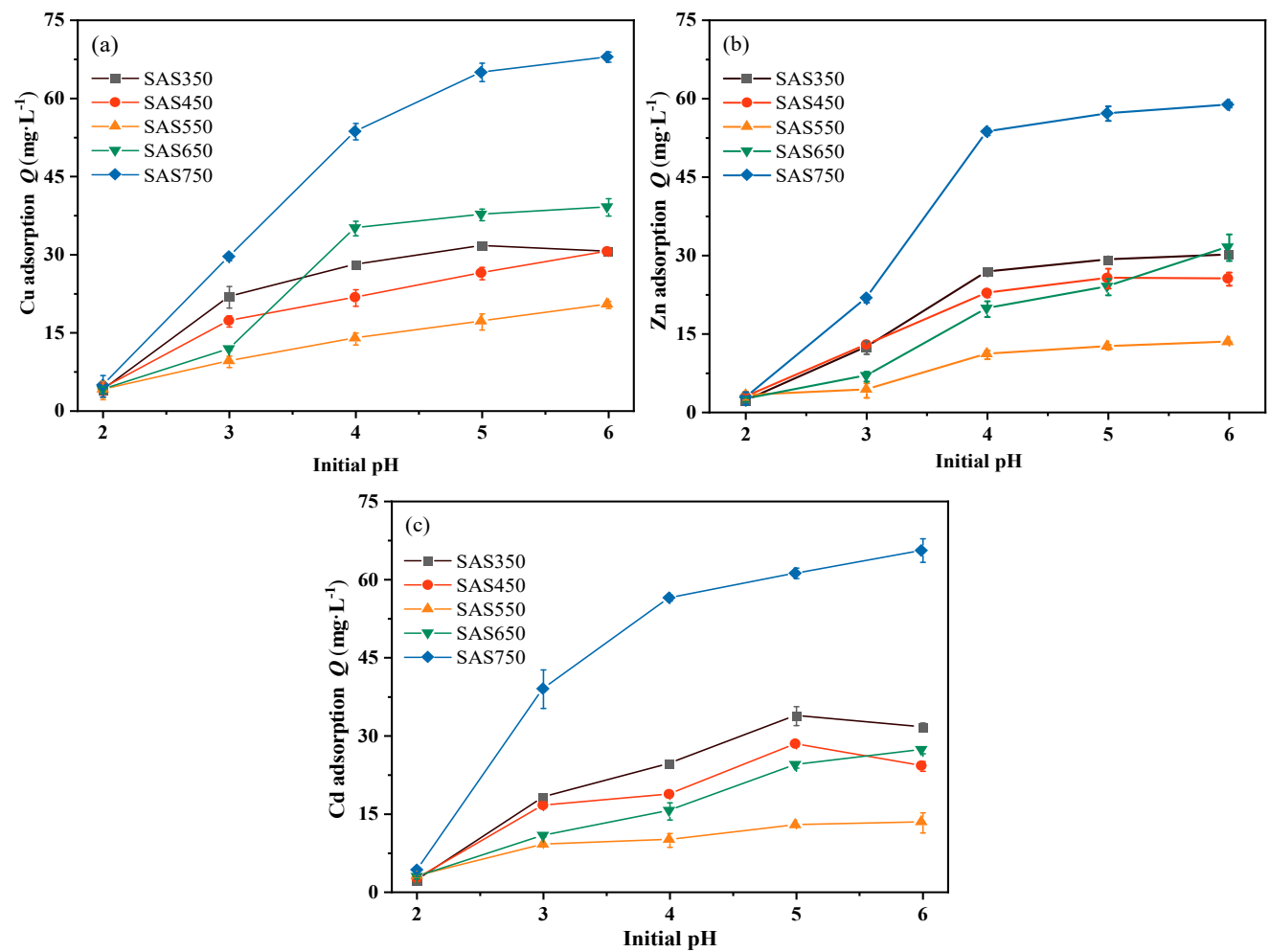

Figure 1. The effects of different solution $\mathrm{pH}$ on the sorption capacity of $\mathrm{Cu}(\mathrm{II})$ (a), $\mathrm{Zn}$ (II) (b), and Cd(II) (c), respectively.
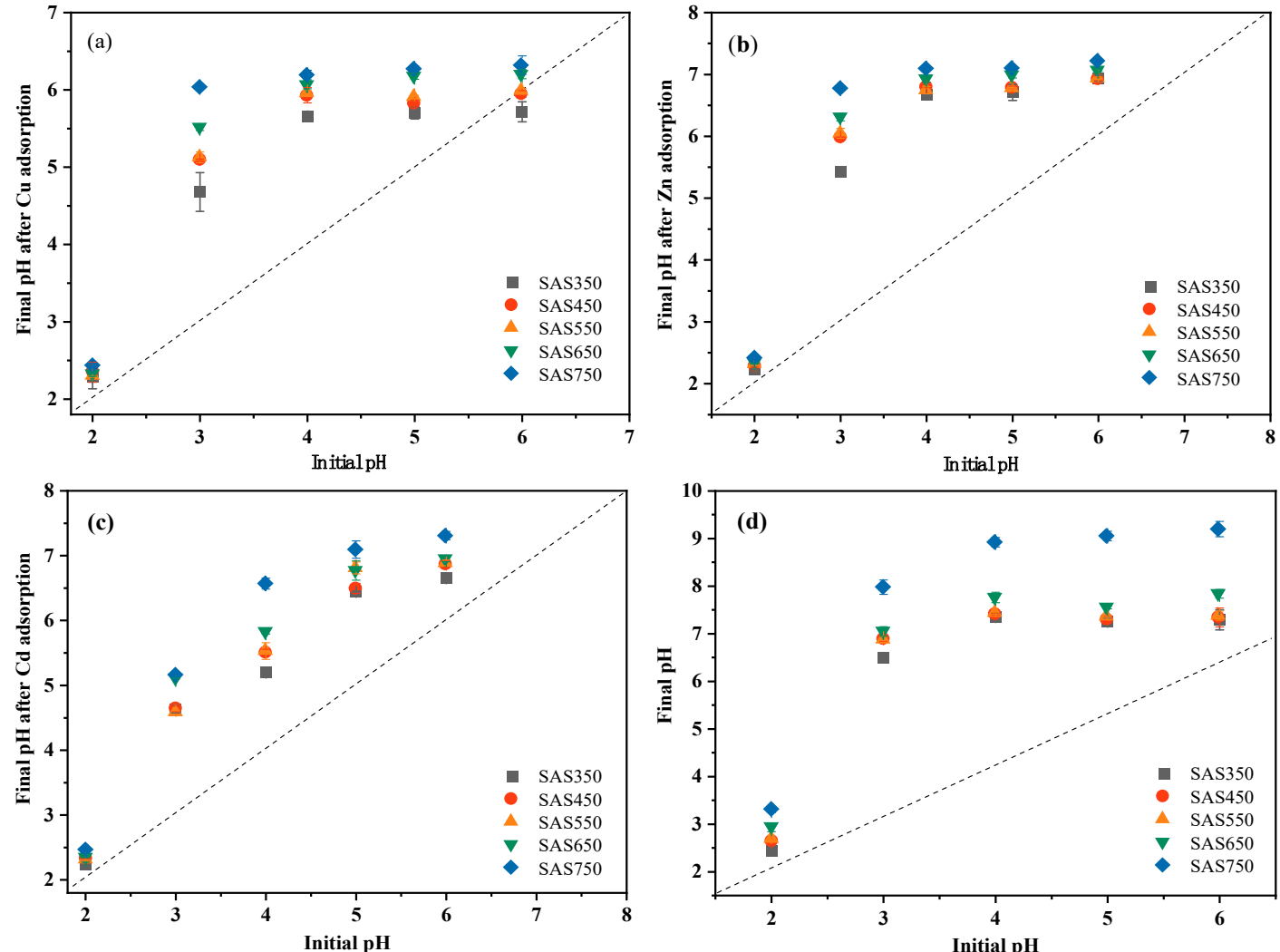

Figure 2. The $\mathrm{pH}$ changes of $\mathrm{Cu}(\mathrm{II})(\mathbf{a}), \mathrm{Zn}(\mathrm{II})(\mathbf{b})$, and $\mathrm{Cd}(\mathrm{II})$ (c) solutions after adsorption equilibrium, respectively. (d) Change of $\mathrm{pH}$ of solution without heavy metals after equilibrium. 

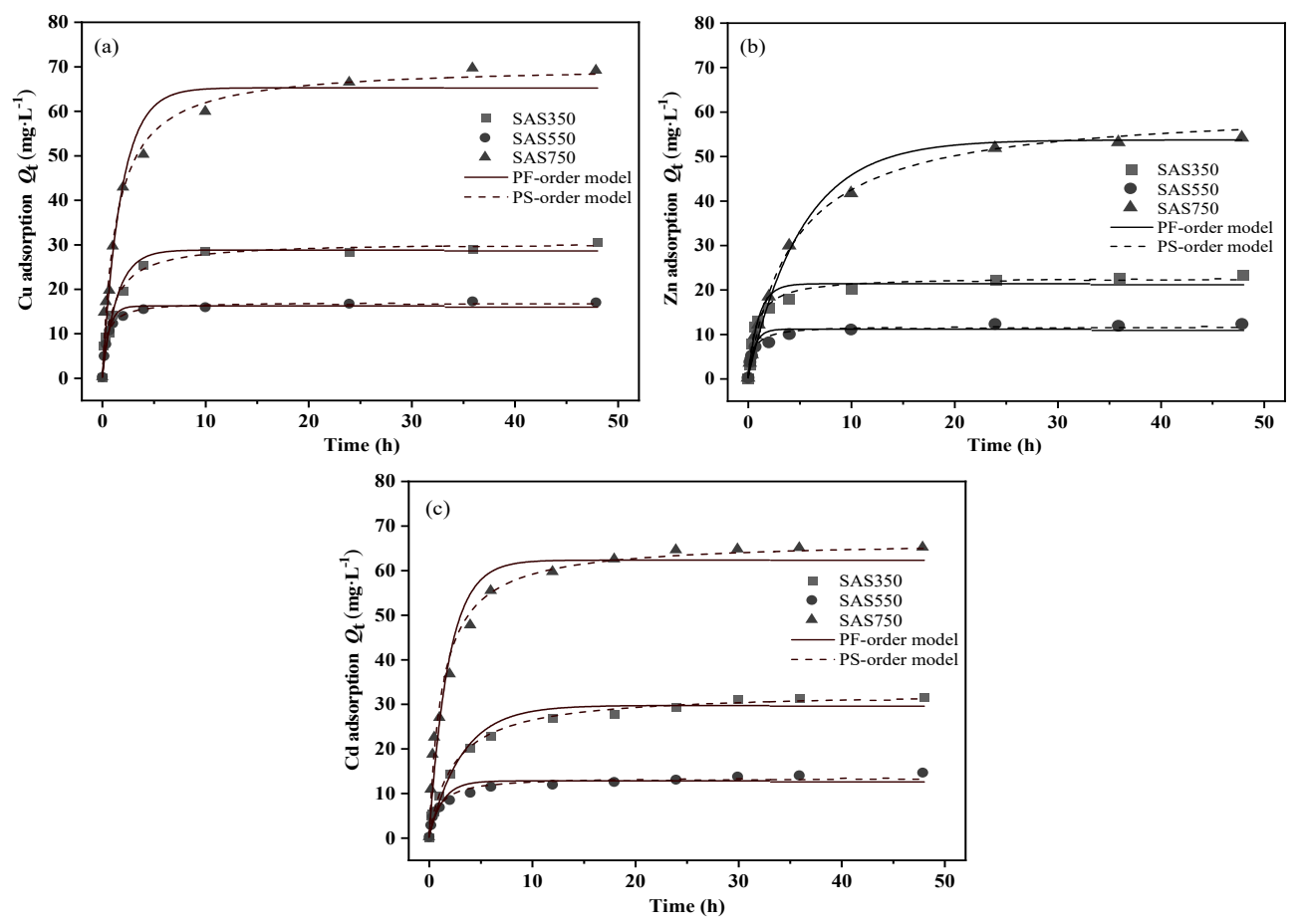

Figure 3. Kinetics of sorption of $\mathrm{Cu}(\mathrm{II})(\mathbf{a}), \mathrm{Zn}(\mathrm{II})(\mathbf{b})$, and $\mathrm{Cd}(\mathrm{II})(\mathbf{c})$ on biochars at 350,550 , and $750{ }^{\circ} \mathrm{C}$.

Minerals in biochars at low temperatures are amorphous and more easily released to bind to heavy metals [42]. Increasing the pyrolysis temperature $\left(>550{ }^{\circ} \mathrm{C}\right)$ causes the minerals in biochars to become more crystalline, which decreases the release rate and limits the corresponding sorption rate. SAS750 requires the longest time to reach equilibrium, which may be due to the lower contribution of functional groups and the higher contribution of minerals in the sorption process (Figure S4).

Pseudo-first-order [43] and pseudo-second-order [44] kinetic models were used to explore the adsorption process of biochars (Figure 3 and Table S2). According to the fitted regression coefficient $\left(R_{2}\right)$, the pseudo-second-order model of the sorption processes of SASCs with various pyrolysis temperatures better described the sorption of $\mathrm{Cu}(\mathrm{II}), \mathrm{Zn}(\mathrm{II})$, and $\mathrm{Cd}(\mathrm{II})$ than the pseudo-first-order. The pseudo-second-order model assumes that the rate-limiting step involves chemical interactions leading to the binding of the ions to the surface by strong covalent bonding [45]. As the reaction kinetics-based models are applicable in the adsorption process, the basic assumption of these models is that the mass transfer is fast enough to be ignored. Accordingly, these models are applied on the chemisorption of solids that are porous, exhibiting high solid-phase diffusion coefficients, in this way, that are appropriate for biochar [45].

The Langmuir and Freundlich models were used to fit the sorption data. The fitting results are presented in Figure 4 and Table S3. The fitting results of the Freundlich model better describe the equilibrium data than those of the Langmuir model; thus, the sorption of SASC was heterogeneous adsorption [46]. All n values exceeded 1.0; hence, SASC had substantial heterogeneity in sorption affinity for $\mathrm{Cu}(\mathrm{II}), \mathrm{Zn}(\mathrm{II})$, and $\mathrm{Cd}(\mathrm{II})$. The Langmuir maximum sorption capacity $\left(Q_{\max }\right)$ followed the order SAS750 > SAS350 > SAS550, and the sorption capacity of SAS750 exceeded those of biochars from other feedstocks that were reported in many studies (Table S3). Overall, for $\mathrm{Cu}$ (II) sorption: $68.1 \mathrm{mg} \cdot \mathrm{g}^{-1}>28.9 \mathrm{mg} \cdot \mathrm{g}^{-1}$ $>11.6 \mathrm{mg} \cdot \mathrm{g}^{-1}$; for $\mathrm{Zn}$ (II) sorption: $55.2 \mathrm{mg} \cdot \mathrm{g}^{-1}>25.6 \mathrm{mg} \cdot \mathrm{g}^{-1}>16.9 \mathrm{mg} \cdot \mathrm{g}^{-1}$; and for Cd(II) sorption: $64.8 \mathrm{mg} \cdot \mathrm{g}^{-1}>47.2 \mathrm{mg} \cdot \mathrm{g}^{-1}>17.2 \mathrm{mg} \cdot \mathrm{g}^{-1}$. These results demonstrate that SAS750 has a higher removal capacity for $\mathrm{Cu}(\mathrm{II}), \mathrm{Zn}(\mathrm{II})$, and $\mathrm{Cd}(\mathrm{II})$. 

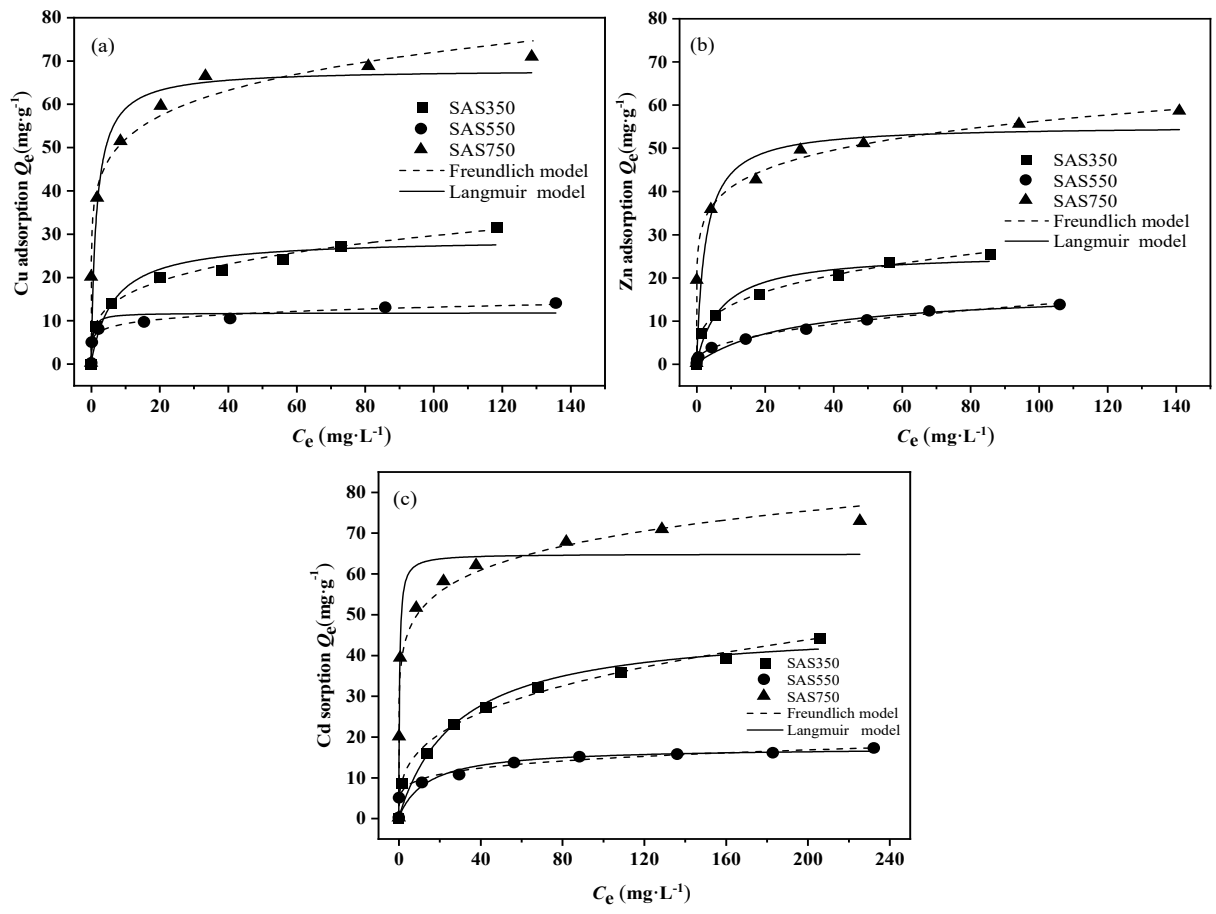

Figure 4. Isotherm model of sorption of $\mathrm{Cu}(\mathrm{II})(\mathbf{a}), \mathrm{Zn}(\mathrm{II}),(\mathbf{b})$ and $\mathrm{Cd}(\mathrm{II})$ (c) on biochars at 350, 550, and $750{ }^{\circ} \mathrm{C}$.

\subsection{Sorption Mechanism Analysis}

To investigate the sorption mechanisms of $\mathrm{Cu}(\mathrm{II}), \mathrm{Zn}(\mathrm{II})$, and $\mathrm{Cd}(\mathrm{II})$ on SASC, samples were scanned via FTIR, XRD, and SEM/EDS before and after sorption.

\subsubsection{Metal Cation Exchange}

Cations on the surface of biochars (e.g., $\mathrm{Ca}^{2+}, \mathrm{K}^{+}, \mathrm{Mg}^{2+}$, and $\mathrm{Na}^{+}$) can exchange with heavy metal ions in solution. To investigate this phenomenon, the release of these cations into solutions that contained and did not contain heavy metals was measured. The results are presented in Figures 5 and 6. In the blank experiment (without heavy metals), many cations were released from the biochar into the solution, especially $\mathrm{Ca}^{2+}$. When the pyrolysis temperature was increased, the total amount of cations that were released from the biochar gradually decreased and reached the lowest value at $650^{\circ} \mathrm{C}$, whereas when the temperature increased to $750{ }^{\circ} \mathrm{C}$, the amount of cations that were released from the biochar increased (Figure 5).

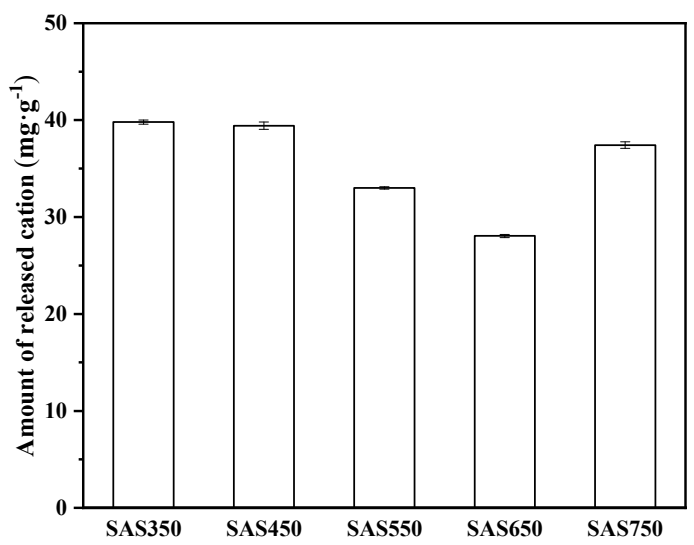

Figure 5. The amount of total cation released from spent Agaricus bisporus substrate biochars (SABCs) into solution (initial $\mathrm{pH}$ of $5,24 \mathrm{~h}$, adsorbent dosage of $1 \mathrm{~g} \cdot \mathrm{L}^{-1}$ ). 


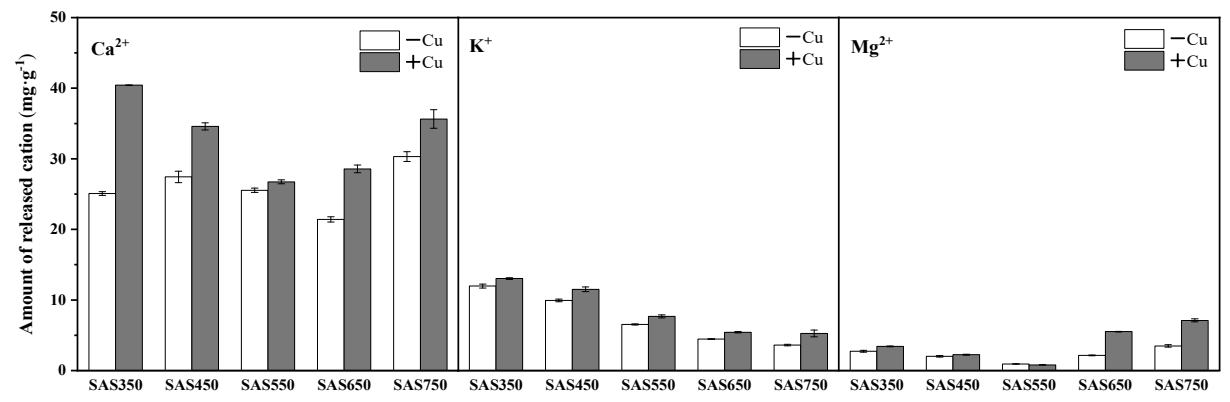

(a) Cu adsorption

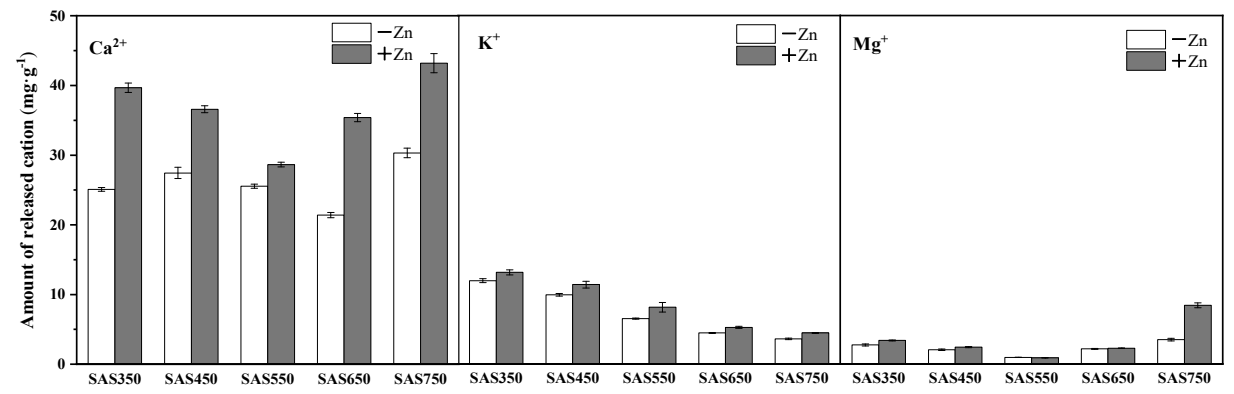

(b) $\mathrm{Zn}$ adsorption

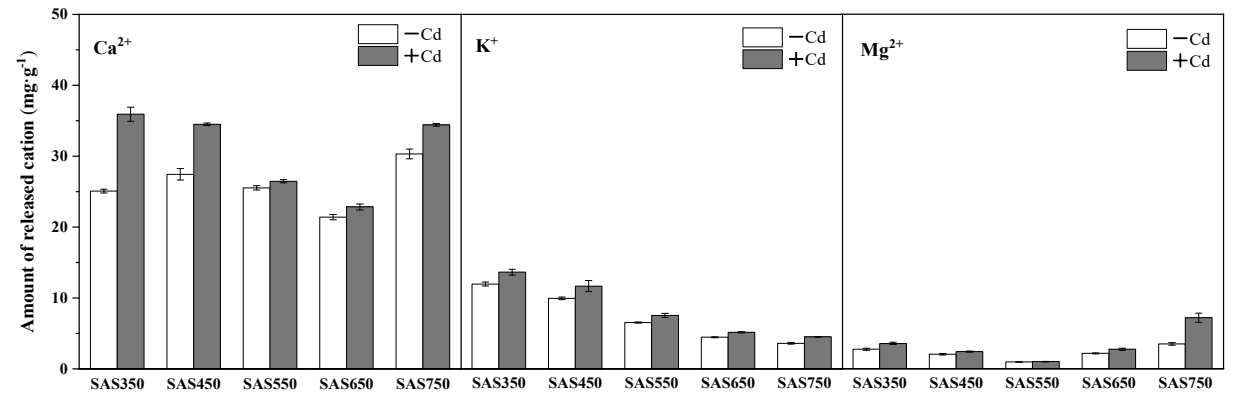

(c) Cd adsorption

Figure 6. The amount of $\mathrm{Ca}^{2+}, \mathrm{K}^{+}$, and $\mathrm{Mg}^{2+}$ released from spent Agaricus bisporus substrate biochars (SABCs) into solution before and after $\mathrm{Cu}(\mathrm{II})(\mathbf{a}), \mathrm{Zn}(\mathrm{II})(\mathbf{b})$, and $\mathrm{Cd}(\mathrm{II})$ (c) adsorption ( $\mathrm{pH}$ of 5, $24 \mathrm{~h}$, initial concentration of $100 \mathrm{mg} \cdot \mathrm{L}^{-1}$ and adsorbent dosage of $\left.1 \mathrm{~g} \cdot \mathrm{L}^{-1}\right)$.

Compared with the blank experiment, the released amounts of $\mathrm{Ca}^{2+}$ and $\mathrm{K}^{+}$in the solution after SASC sorption (containing heavy metals) increased, while the released amount of $\mathrm{Mg}^{2+}$ changed substantially only in SAS750. (Figure 6) In most cases [47], the cation exchange during the sorption of low-temperature biochar $\left(\sim 550{ }^{\circ} \mathrm{C}\right)$ was stronger than that at high-temperature $\left(\approx 750^{\circ} \mathrm{C}\right)$. In this study, it was found that the increment of cation release from the solution after the pyrolyzed biochar adsorbed heavy metals at $550{ }^{\circ} \mathrm{C}$ was apparently lower than those at other pyrolysis temperatures. For example, for the sorption of $\mathrm{Cu}(\mathrm{II})$, the samples are ordered according to the total amount of cations that were released as follows: SAS550 $\left(3.23 \mathrm{mg} \cdot \mathrm{g}^{-1}\right)<\mathrm{SAS} 650<\left(9.49 \mathrm{mg} \cdot \mathrm{g}^{-1}\right)<$ SAS450 $\left(9.61 \mathrm{mg} \cdot \mathrm{g}^{-1}\right)$ SAS750 $<\left(11.59 \mathrm{mg} \cdot \mathrm{g}^{-1}\right)<$ SAS350 $\left(18.09 \mathrm{mg} \cdot \mathrm{g}^{-1}\right)$. The reasons for this could be mainly attributed to the structure of crystalline minerals at $550{ }^{\circ} \mathrm{C}$ [21]. These results demonstrate that the pyrolysis temperature affects the process of cation exchange in the sorption of heavy metals by spent mushroom substrate biochar.

\subsubsection{Precipitation with Minerals}

Anions that are released from biochar (e.g., $\mathrm{OH}^{-}, \mathrm{CO}_{3}{ }^{2-}, \mathrm{PO}_{4}{ }^{3-}$, and $\mathrm{SO}_{4}{ }^{2-}$ ) can precipitate with heavy metal ions. According to a previous prediction, mineral precipitation will play an important role in the sorption process of SASCs, especially for biochars under high-temperature pyrolysis. To evaluate the role of precipitation in the sorption process, biochars before and after sorption were scanned using XRD (Figure 7a). The calcium- 
containing minerals that were added into the culture medium of Agaricus bisporus as the calcium source were not completely absorbed by Agaricus bisporus, and calcium sulfate $\left(\mathrm{CaSO}_{4}\right)$, dolomite $\left(\mathrm{CaMg}\left(\mathrm{CO}_{3}\right)_{2}\right)$, and calcite $\left(\mathrm{CaCO}_{3}\right)$ were detected after pyrolysis via XRD (Figure 7a). With increasing temperature, $\mathrm{CaSO}_{4}$ peaks disappeared, while $\mathrm{CaCO}_{3}$ peaks were newly formed in SAS650 and SAS750. Meanwhile, the peak of $\mathrm{CaMg}\left(\mathrm{CO}_{3}\right)_{2}$ weakened until it disappeared at $750{ }^{\circ} \mathrm{C}$. Consistent with the results of the EDS spectra (Figure $\mathrm{S} 1$ ), there were strong peaks that were attributed to $\mathrm{SiO}_{2}$ in the XRD patterns of each biochar; hence, $\mathrm{SiO}_{2}$ was abundant in SASC.
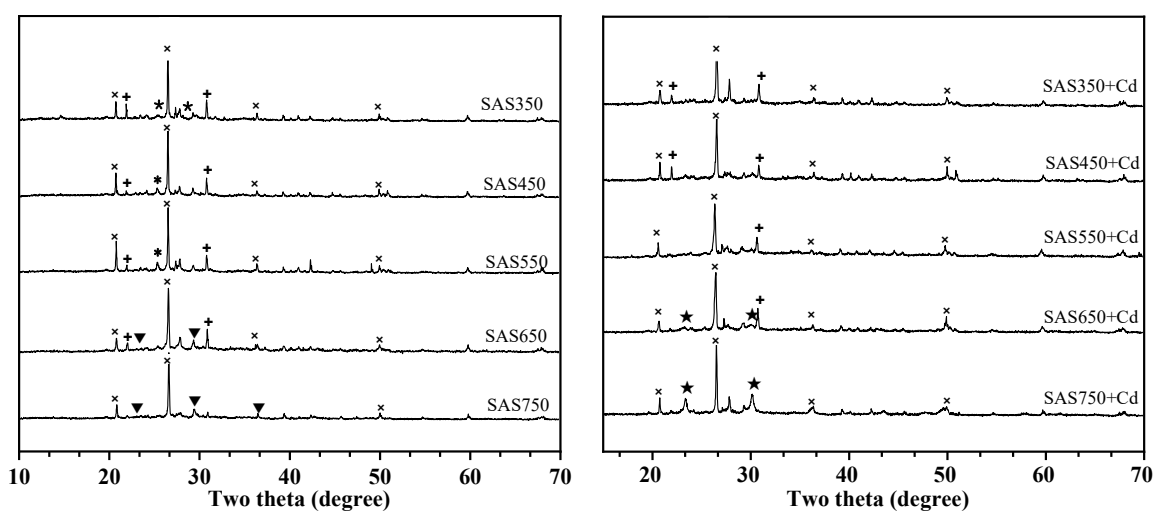

(a)

(d)

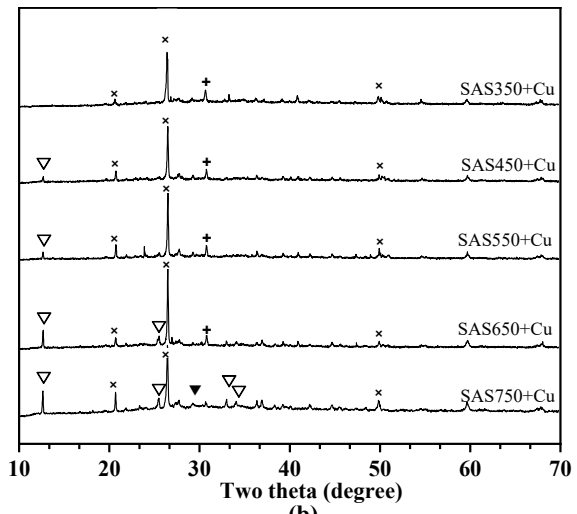

(b)

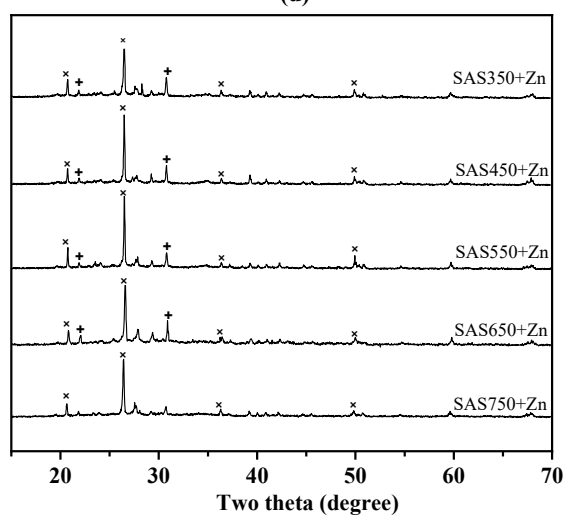

(c)

Figure 7. X-ray diffraction (XRD) patterns of biochars before (a) and after adsorbed with metal of $\mathrm{Cu}(\mathrm{II})(\mathbf{b}), \mathrm{Zn}(\mathrm{II})(\mathbf{c})$, or $\mathrm{Cd}(\mathrm{II})(\mathbf{d})$. Minerals with peaks labeled $\times$, quartz $\left(\mathrm{SiO}_{2}\right) ;$; , calcite $\left(\mathrm{CaSO}_{4}\right) ; \boldsymbol{\nabla}$, calcium carbonate $\left(\mathrm{CaCO}_{3}\right) ; \boldsymbol{\mathbf { }}$, dolomite $\left(\mathrm{CaMg}\left(\mathrm{CO}_{3}\right)_{2}\right) ; \nabla$, posnjakite $\left(\mathrm{Cu}_{4} \mathrm{SO}_{4}(\mathrm{OH})_{6} \mathrm{H}_{2} \mathrm{O}\right) ; \star$, Otavite $\left(\mathrm{CdCO}_{3}\right)$.

Compared with unabsorbed samples, new peaks that represented precipitates were observed for the samples after $\mathrm{Cd}$ (II) and $\mathrm{Cu}$ (II) sorption, especially for biochars under hightemperature pyrolysis $\left(>550{ }^{\circ} \mathrm{C}\right)$. After the sorption of $\mathrm{Cu}(\mathrm{II})$, posnjakite $\left(\mathrm{Cu}_{4}\left(\mathrm{SO}_{4}\right)(\mathrm{OH})_{6}\right.$ $\left(\mathrm{H}_{2} \mathrm{O}\right)$ ) was formed (Figure $7 \mathrm{~b}$ ), and the peak intensity increased with the pyrolysis temperature. After the sorption of $\mathrm{Cd}(\mathrm{II})$, new peaks of Otavite $\left(\mathrm{CdCO}_{3}\right)$ were formed in SAS650 and SAS750 (Figure 7d). No precipitate was readily identified in the XRD spectra after the sorption of $\mathrm{Zn}(\mathrm{II})$. This result suggests that no significant precipitation occurred during the sorption of Zn(II). Compared with other samples, SAS750 showed the highest sorption capacity for each heavy metal; hence, it was chosen for the SEM and EDS analyses (Figure S2). Compared with nonadsorbed biochars, many precipitates were observed in the SEM images of SAB750 after heavy metal adsorption, which were flocculent for Cd and flaky for $\mathrm{Cu}$ and $\mathrm{Zn}$. The EDS spectra further showed the elemental composition (Figure S2), and it was found that the presence of $\mathrm{Cd}, \mathrm{Cu}$, and $\mathrm{Zn}$ elements and the proportion of $\mathrm{Ca}$ elements in the samples decreased significantly after sorption. These results 
supported the important roles of mineral precipitation and cation exchange in the sorption process of high-temperature biochars.

\subsubsection{Oxygen Functional Group and $\pi$ Electrons}

FTIR spectra before and after sorption are shown in Figure 8. Functional groups (e.g., $\mathrm{C}=\mathrm{C},-\mathrm{COOH},-\mathrm{OH}$, and $\mathrm{R}-\mathrm{OH}$ ) in biochar have an important influence on the sorption process of heavy metals [48]. The typical bands at $3420 \mathrm{~cm}^{-1}$ are attributed to $-\mathrm{OH}$ vibrations, the bands at $2950-2850 \mathrm{~cm}^{-1}$ are attributed to aliphatic C-H stretching $[49,50]$, the bands at $1620 \mathrm{~cm}^{-1}$ are attributed to $\mathrm{C}=\mathrm{O}$ vibrations of carboxyl groups, and the bands at $1319 \mathrm{~cm}^{-1}$ are attributed to $\mathrm{C}-\mathrm{O}$ peaks. $\mathrm{C}=\mathrm{C}$ skeleton vibration of the aromatic ring corresponds to the band at $1427 \mathrm{~cm}^{-1}$, and C-H bending vibration of the aromatic ring corresponds to the band at $800-600 \mathrm{~cm}^{-1}\left(778,675,595 \mathrm{~cm}^{-1}\right)$ [51]. The band at $1110 \mathrm{~cm}^{-1}$ can be attributed to $\mathrm{SO}_{4}{ }^{2-}$.

After the pyrolysis temperature was increased, the vibration of the corresponding $-\mathrm{OH}$ gradually weakened, the aliphatic $\mathrm{C}-\mathrm{H}$ stretching weakened and disappeared, the $\mathrm{C}-\mathrm{O}$ stretching disappeared at temperatures above $450^{\circ} \mathrm{C}$, and the $\mathrm{C}=\mathrm{O}$ vibration of the carboxyl group continued to weaken. In addition, the $\mathrm{SO}_{4}{ }^{2-}$ stretching continuously weakened as the temperature was increased to $550{ }^{\circ} \mathrm{C}$. The corresponding vibration of aromatics was enhanced with increasing temperature, and the enhancement of the aromaticity can provide more $\pi$ electrons to bind with heavy metals. In addition, the related vibrations at $875 \mathrm{~cm}^{-1}$ were assigned to $\mathrm{CO}_{3}{ }^{2-}$ [22], and the vibrations of Si-O-Si at $465 \mathrm{~cm}^{-1}$ and $1030 \mathrm{~cm}^{-1}$ were assigned to $\mathrm{SiO}_{2}$, which was consistent with the XRD analysis results.

After sorption, each functional group changed, and the position of the corresponding peak shifted (Figure $8 \mathrm{~b}-\mathrm{f})$. For example, the peaks at 1620, 1319, and $1100 \mathrm{~cm}^{-1}(\mathrm{C}=\mathrm{O}$, $\mathrm{C}-\mathrm{O}$, and $\mathrm{C}-\mathrm{O}-\mathrm{C}$ vibrations, respectively) were weakened, while the changes in the oxygen functional groups of low-temperature biochars were more obvious; thus, more oxygen functional groups were involved in the sorption of low-temperature pyrolysis biochars. In addition, the $\mathrm{pH}$ value of the solution decreased after the sorption of acid-washed biochar, which also supported the involvement of the oxygen functional groups in the sorption process.

In addition to oxygen functional groups, other functional group components (aromatic $\mathrm{C}=\mathrm{C}$ and $\mathrm{C}-\mathrm{H}$ ) have also been demonstrated to be involved in the sorption process, especially the interactions of $\pi$ with $\mathrm{Cu}(\mathrm{II}), \mathrm{Zn}(\mathrm{II})$, and $\mathrm{Cd}(\mathrm{II})$. It is observed that the $\mathrm{C}-\mathrm{H}$ vibration of the peak at $800 \sim 600 \mathrm{~cm}^{-1}$ continues to weaken or be displaced. Especially for $\mathrm{Cu}(\mathrm{II})$ and $\mathrm{Zn}$ (II) sorption, the $\mathrm{C}=\mathrm{C}$ change at $1427 \mathrm{~cm}^{-1}$ at high temperatures $\left(\geq 650^{\circ} \mathrm{C}\right)$ is more drastic, which is attributed to the high degree of graphitization at high pyrolysis temperatures. At high temperatures $\left(\geq 650{ }^{\circ} \mathrm{C}\right)$, the change that corresponds to the $\mathrm{CO}_{3}{ }^{2-}$ peak at $875 \mathrm{~cm}^{-1}$ became more obvious; thus, more $\mathrm{CO}_{3}{ }^{2-}$ participated in the precipitation reaction at high temperatures and less participated at low temperatures.

\subsection{Contributions of the $\mathrm{Cu}(\mathrm{II}), \mathrm{Zn}(\mathrm{II})$, and $\mathrm{Cd}(\mathrm{II})$ Sorption Mechanisms}

The contributions of various mechanisms to the process of heavy metal sorption by biochars were evaluated according to the method that is described in the Materials and Methods section. The contribution amounts and contribution proportions of various sorption mechanisms are presented in Figure 9 and Table S4. In the sorption of the three considered heavy metals, the contribution of $\pi$ coordination $\left(\mathrm{Q}_{\mathrm{c} \pi}\right)$ gradually increased as the pyrolysis temperature was increased $\left(350-750^{\circ} \mathrm{C}\right)$, while the contribution of oxygencontaining functional group complexation $\left(\mathrm{Q}_{\mathrm{co}}\right)$ showed the opposite trend. For instance, in the process of SASC adsorption of $\mathrm{Cu}(\mathrm{II}), \mathrm{Q}_{\mathrm{c} \pi}$ increased from 5.52 to $6.66 \mathrm{mg} \cdot \mathrm{g}^{-1}$ with increasing temperature $\left(350-750{ }^{\circ} \mathrm{C}\right)$, while $\mathrm{Q}_{\mathrm{co}}$ and $\mathrm{Q}_{\mathrm{co}} / \mathrm{Q}_{\mathrm{t}}$ decreased from $5.81 \mathrm{mg} \cdot \mathrm{g}^{-1}$ and $18.4 \%$ to $1.62 \mathrm{mg} \cdot \mathrm{g}^{-1}$ and $2.0 \%$, respectively. This phenomenon may be due to the reserved amount of oxygen functional groups and the strength of the aromaticity, which are affected by the pyrolysis temperature. The sorption of $\mathrm{Cu}(\mathrm{II})$ and $\mathrm{Zn}$ (II) by different mechanisms showed similar trends. 


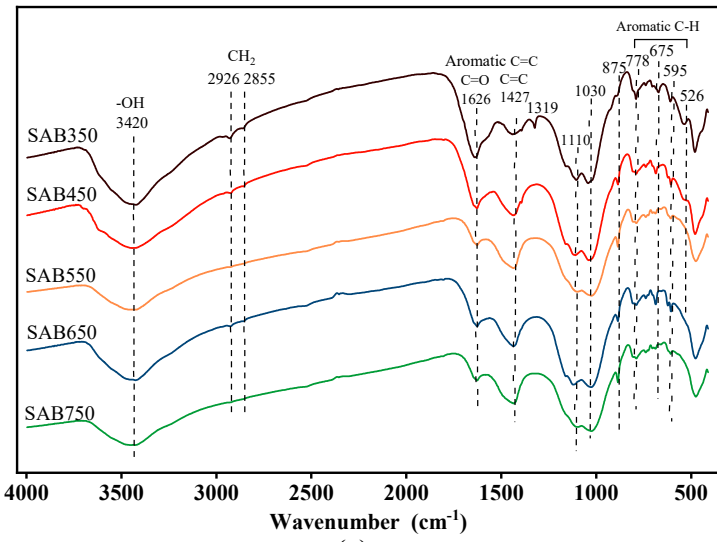

(a)

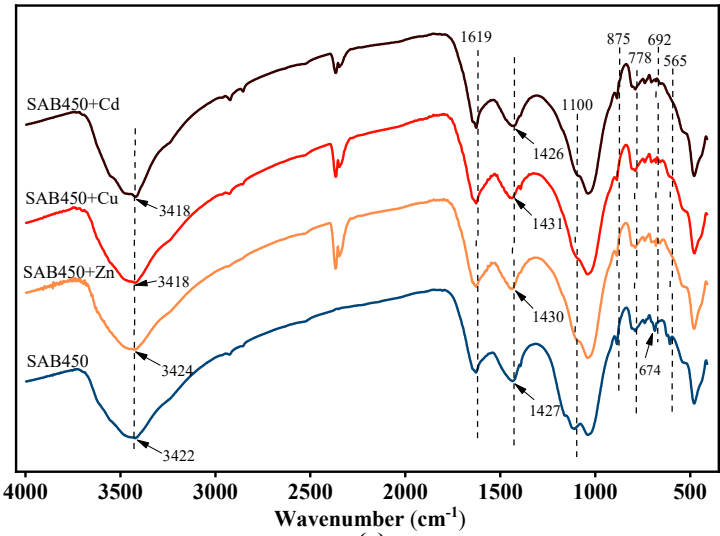

(c)

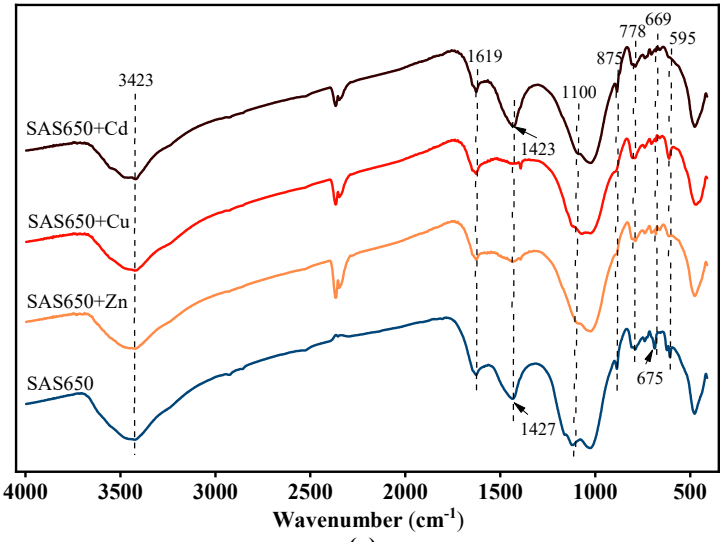

(e)

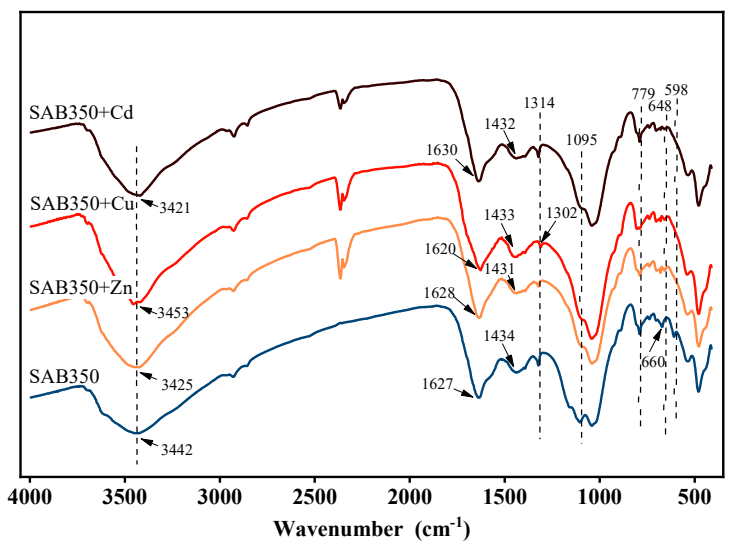

(b)

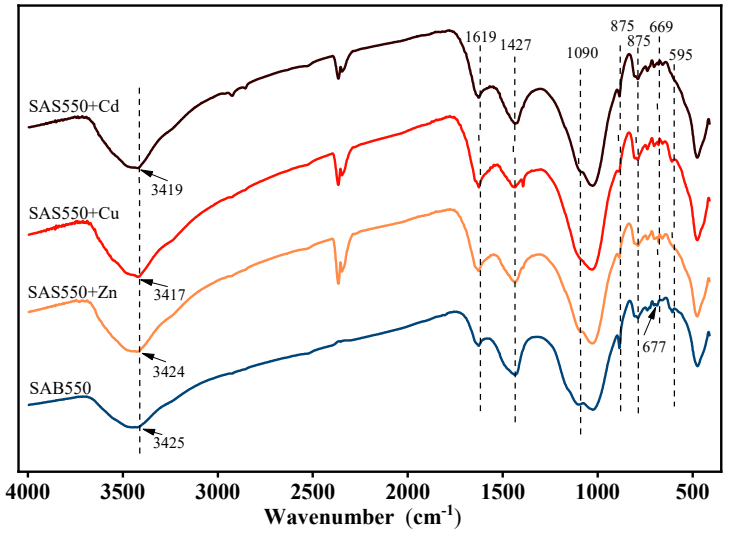

(d)

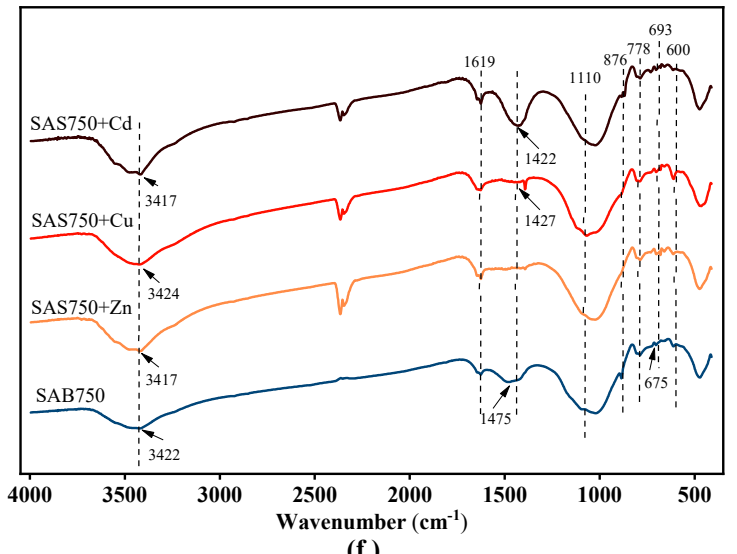

(f)

Figure 8. (a) Fourier transform infrared spectra (FTIR) spectra of biochar at $350-750{ }^{\circ} \mathrm{C}$ pyrolysis temperature. FTIR spectra of SAS350 (b), SAS450 (c), SAS550 (d), SAS650 (e), and SAS750 (f) before and after sorption.

The variation rules of $Q_{c o}$ and $Q_{c \pi}$ are strongly influenced by the amount of oxygencontaining functional groups and the aromaticity in biochars. FTIR analysis showed that pyrolysis enhanced the aromaticity and decomposition of oxygen-containing functional groups in SASCs, thereby resulting in a gradual decrease in the contribution of oxygen functional groups to sorption, while the role of $\pi$ electrons was constantly enhanced. 

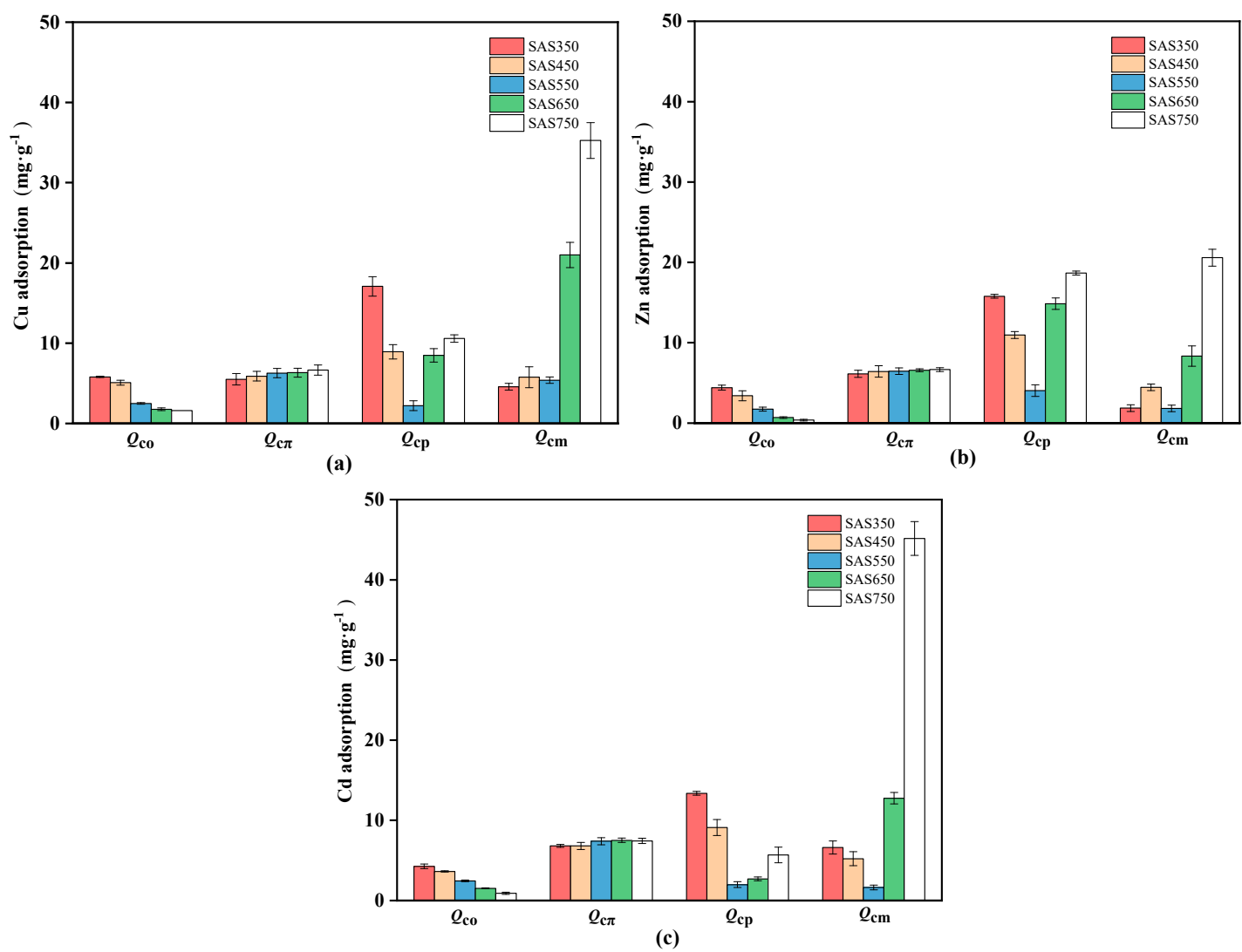

Figure 9. The change of contributions of different adsorption mechanisms with temperature during $\mathrm{Cu}(\mathrm{II})$ (a), $\mathrm{Zn}$ (II) (b), and $\mathrm{Cd}(\mathrm{II})(\mathrm{c})$ adsorption ( $\mathrm{pH}$ of $5,24 \mathrm{~h}$, initial concentration of $100 \mathrm{mg} \cdot \mathrm{L}^{-1}$ and adsorbent dosage of $1 \mathrm{~g} \cdot \mathrm{L}^{-1}$ ).

The change in the cation exchange contribution $\left(\mathrm{Q}_{\mathrm{ce}}\right)$ with temperature was substantial in several sorption mechanisms. When the pyrolysis temperature was between 350 and $550{ }^{\circ} \mathrm{C}$, the cation exchange $\left(\mathrm{Q}_{\mathrm{ce}}\right)$ decreased with the increasing pyrolysis temperature, whereas when the pyrolysis temperature was increased from 550 to $750{ }^{\circ} \mathrm{C}, \mathrm{Q}_{\mathrm{cp}}$ showed the opposite upward trend. The values of $\mathrm{Q}_{\mathrm{ce}}$ for $\mathrm{Cu}(\mathrm{II}), \mathrm{Zn}(\mathrm{II})$, and $\mathrm{Cd}(\mathrm{II})$ sorption were only 2.23, 1.83, and $4.05 \mathrm{mg} \cdot \mathrm{g}^{-1}$, respectively, for SAS550. The abrupt decrease in $\mathrm{Q}_{c e}$ in SAS550 resulted in the weakest sorption performance. Lower pyrolysis temperatures were conducive to the sorption of heavy metals via cation exchange mechanisms, at which time biochar had a lower degree of carbonization and could release many available mineral components (such as $\mathrm{Ca}^{+}$and $\mathrm{K}^{+}$). When the pyrolysis temperature was increased from 350 to $550{ }^{\circ} \mathrm{C}$, the mineral components in SASC became more crystalline [52], and the solubility decreased, thereby resulting in a decrease in the cation exchange capacity. When the pyrolysis temperature was further increased $\left(>650^{\circ} \mathrm{C}\right)$, the cation exchange capacity did not continue to decline but began to increase. At this pyrolysis temperature, high-temperature pyrolysis resulted in a change in the mineral crystals in SASC with the production of new minerals [41] (Figure 7a; $\mathrm{CaMg}\left(\mathrm{CO}_{3}\right)_{2}$ is converted to $\mathrm{CaCO}_{3}$ ), thereby resulting in the solubility of minerals in the biochar being no longer reduced, which was manifested as enhanced exchange of $\mathrm{Ca}^{2+}$ and $\mathrm{Mg}^{2+}$ cations with heavy metal ions (Table S3)

Compared with the high pyrolysis temperature, a small amount of precipitation occurred during the sorption process of the biochar at low temperatures $\left(350-550{ }^{\circ} \mathrm{C}\right)$. The XRD pattern showed a weak representative precipitate peak (for $\mathrm{Cu}(\mathrm{II})$ ) or no readily observable precipitate (for Cd(II) and Zn(II)) (Figure 7c,d), especially for SAS350 after sorption. The mineral precipitation ratios in the sorption of the high-pyrolysis-temperature biochars (SAS650 and SAS750) increased (as shown in Figure 7c,d); this change was also demonstrated by the XRD pattern. 
Overall, the pyrolysis temperature affects the ability of biochars to adsorb heavy metals, and the dominant mechanism of biochar adsorption of heavy metals differs among pyrolysis temperatures. For the organic components $\left(Q_{c \pi}+Q_{c o}\right)$, the contribution gradually decreased with increasing temperature, while the inorganic components $\left(Q_{c e}+Q_{c p}\right)$ were more substantially affected by the pyrolysis temperature, and the contribution initially decreased and subsequently increased. The optimal production temperature is $750{ }^{\circ} \mathrm{C}$ for pyrolysis. At this temperature, the contribution of the mineral precipitation increased substantially, the sorption amount reached its maximum value, and the $Q_{c p} / Q_{t}$ values for $\mathrm{Cu}(\mathrm{II}), \mathrm{Zn}(\mathrm{II})$, and $\mathrm{Cd}(\mathrm{II})$ were $63.4 \%, 44.4 \%$, and $71.2 \%$, respectively.

\section{Conclusions}

Mineral-rich biochar that was derived from a spent Agaricus bisporus substrate showed the effective removal of $\mathrm{Cu}(\mathrm{II}), \mathrm{Zn}(\mathrm{II})$, and $\mathrm{Cd}(\mathrm{II})$ from aqueous solutions, and the sorption performance was affected by the pyrolysis temperature and the solution $\mathrm{pH}$ value. The pyrolysis temperature of $750{ }^{\circ} \mathrm{C}$ yields the best adsorbent. According to mechanistic investigations, mineral components play a key role in biochar sorption, which is mainly through cation exchange at low pyrolysis temperatures (e.g., $350^{\circ} \mathrm{C}$ ), whereas mineral precipitation plays a major role at high temperatures (e.g., $750{ }^{\circ} \mathrm{C}$ ). In conclusion, the results suggested that the production of a mineral-rich biochar from a spent Agaricus bisporus substrate for the removal of heavy metals from aqueous solutions is a promising method for the utilization of abandoned spent mushroom substrates.

Supplementary Materials: The following are available online at https:/ /www.mdpi.com/1996-194 4/14/1/35/s1; Mathematical models for adsorption kinetics and isotherm; Table S1: The concentrations of metals in biochars derived from spent Agaricus bisporus substrate; Table S2: Pseudo-first (PF) order and pseudo-second (PS) order model parameters for the Cd(II), Cu(II), or Zn(II) sorption onto SAS-derived biochars produced at 350, 550, and $750{ }^{\circ} \mathrm{C}$.; Table S3: Langmuir and Freundlich isotherm parameters for $\mathrm{Cd}(\mathrm{II}), \mathrm{Cu}(\mathrm{II})$, or $\mathrm{Zn}(\mathrm{II})$ sorption onto SAS-derived biochars produced at 350, 550, and $750{ }^{\circ} \mathrm{C}$; Table S4: Comparison of SASC adsorption capacity of $\mathrm{Cd}(\mathrm{II}), \mathrm{Cu}(\mathrm{II})$, and $\mathrm{Zn}$ (II) with other biochar; Figure S1: The SEM images $(3000 \times)$ and corresponding EDS spectra of spent Agaricus bisporus derived biochars at $350-750{ }^{\circ} \mathrm{C}$; Figure S2: The SEM images $(3000 \times)$ and corresponding EDS spectra of spent Agaricus bisporus derived biochars after adsorption of $\mathrm{Cd}(\mathrm{II}), \mathrm{Cu}(\mathrm{II})$, and $\mathrm{Zn}$ (II) at $750{ }^{\circ} \mathrm{C}$; Figure S3: The amount of $\mathrm{Ca} 2+, \mathrm{K}+$ and $\mathrm{Mg} 2+$ released from SABCs into solution after $\mathrm{Zn}(\mathrm{II})$ adsorption at different initial $\mathrm{pH}$ values; Figure S4: The contribution percentage of different mechanisms to $\mathrm{Cu}(\mathrm{II})(\mathrm{a}), \mathrm{Zn}(\mathrm{II})(\mathrm{b})$, and Cd(II) (c) sorption on SASCs.

Author Contributions: G.Z. designed the study, performed the experiments, analyzed the data, and wrote the manuscript; N.L. and Y.L. did the writing-review and editing, analyzed the data; H.Z. and L.S. provided the resources, formal analysis; H.C. and K.O. project administration, supervision funding acquisition. All authors have read and agreed to the published version of the manuscript.

Funding: This research was funded by Natural Science Foundation of Shanxi Province, China (Grant No. 201901D111216); the Major Coal Based Science and Technology Project of Shanxi Province, China (Grant No. FT2014-03); the Key Research and Development Program of Shanxi Province, China (Grant No. 201903D211012-05).

Informed Consent Statement: "Not applicable" for studies not involving humans.

Data Availability Statement: The data presented in this study are available in supplementary material.

Acknowledgments: Special thanks to the Edible Fungus Center of Shanxi Agricultural University for the supplying of the experiment materials.

Conflicts of Interest: The authors declare no conflict of interest.

\section{References}

1. Hřebečková, T.; Wiesnerová, L.; Hanč, A. Change in agrochemical and biochemical parameters during the laboratory vermicomposting of spent mushroom substrate after cultivation of Pleurotus ostreatus. Sci. Total Environ. 2020, $739,140085$. [CrossRef] 
2. Lin, Y.; Ge, X.; Li, Y. Solid-state anaerobic co-digestion of spent mushroom substrate with yard trimmings and wheat straw for biogas production. Bioresour. Technol. 2014, 169, 468-474. [CrossRef] [PubMed]

3. González-Marcos, A.; Alba-Elías, F.; Martínez-de-Pisón, F.J.; Alfonso-Cendón, J.; Castejón-Limas, M. Composting of Spent Mushroom Substrate and Winery Sludge. Compos. Sci. Util. 2015, 23, 58-65. [CrossRef]

4. Meng, X.; Liu, B.; Zhang, H.; Wu, J.; Yuan, X.; Cui, Z. Co-composting of the biogas residues and spent mushroom substrate: Physicochemical properties and maturity assessment. Bioresour. Technol. 2019, 276, 281-287. [CrossRef] [PubMed]

5. Leiva, F.J.; García, J.; Martínez, E.; Jiménez, E.; Blanco, J. Scenarios for the reduction of environmental impact in Agaricus bisporus production. J. Clean. Prod. 2017, 143, 200-211. [CrossRef]

6. Yong, Z.; Ji, C.; Feng, Z. The spatiotemporal distribution of pollutant emissions from open burning of spent mushroom substrate in China. China Environ. Sci. 2020, 40, 100-108.

7. Wei, D.; Li, B.; Huang, H.; Luo, L.; Zhang, J.; Yang, Y.; Guo, J.; Tang, L.; Zeng, G.; Zhou, Y. Biochar-based functional materials in the purification of agricultural wastewater: Fabrication, application and future research needs. Chemosphere 2018, 197, 165-180. [CrossRef] [PubMed]

8. Ahmad, M.; Rajapaksha, A.U.; Lim, J.E.; Zhang, M.; Bolan, N.; Mohan, D.; Vithanage, M.; Lee, S.S.; Ok, Y.S. Biochar as a sorbent for contaminant management in soil and water: A review. Chemosphere 2014, 99, 19-33. [CrossRef] [PubMed]

9. Wang, Y.; Liu, Y.; Zhan, W.; Zheng, K.; Wang, J.; Zhang, C.; Chen, R. Stabilization of heavy metal-contaminated soils by biochar: Challenges and recommendations. Sci. Total Environ. 2020, 729, 139060. [CrossRef]

10. Xue, Y.; Gao, B.; Yao, Y.; Inyang, M.; Zhang, M.; Zimmerman, A.R.; Ro, K.S. Hydrogen peroxide modification enhances the ability of biochar (hydrochar) produced from hydrothermal carbonization of peanut hull to remove aqueous heavy metals: Batch and column tests. Chem. Eng. J. 2012, 200-202, 673-680. [CrossRef]

11. Guo, S.; Xu, Z.; Li, F.; Xu, D. Adsorption of $\mathrm{Pb}(\mathrm{II}), \mathrm{Zn}(\mathrm{II})$ from aqueous solution by biochars. Chin. J. Environ. Eng. 2015, $9,3215-3222$.

12. Teng, D.; Zhang, B.; Xu, G.; Wang, B.; Mao, K.; Wang, J.; Sun, J.; Feng, X.; Yang, Z.; Zhang, H. Efficient removal of Cd(II) from aqueous solution by pinecone biochar: Sorption performance and governing mechanisms. Environ. Pollut. 2020, $265,115001$. [CrossRef] [PubMed]

13. Wang, S.; Kwak, J.-H.; Islam, M.S.; Naeth, M.A.; Gamal El-Din, M.; Chang, S.X. Biochar surface complexation and Ni(II), Cu(II), and Cd(II) adsorption in aqueous solutions depend on feedstock type. Sci. Total Environ. 2020, 712, 136538. [CrossRef] [PubMed]

14. Chen, X.; Chen, G.; Chen, L.; Chen, Y.; Lehmann, J.; McBride, M.B.; Hay, A.G. Adsorption of copper and zinc by biochars produced from pyrolysis of hardwood and corn straw in aqueous solution. Bioresour. Technol. 2011, 102, 8877-8884. [CrossRef] [PubMed]

15. Li, X.; Lei, T.; Wang, Z.; Li, X.; Wen, M.; Yang, M.; Chen, G.; He, X.; Xu, H.; Guan, Q.; et al. Catalytic pyrolysis of corn straw with magnetic solid acid catalyst to prepare levulinic acid by response surface methodology. Ind. Crop. Prod. 2018, 116, 73-80. [CrossRef]

16. Deng, Y.; Huang, S.; Dong, C.; Meng, Z.; Wang, X. Competitive adsorption behaviour and mechanisms of cadmium, nickel and ammonium from aqueous solution by fresh and ageing rice straw biochars. Bioresour. Technol. 2020, 303, 122853. [CrossRef]

17. Park, J.H.; Wang, J.J.; Kim, S.H.; Cho, J.S.; Kang, S.W.; Delaune, R.D.; Han, K.J.; Seo, D.C. Recycling of rice straw through pyrolysis and its adsorption behaviors for $\mathrm{Cu}$ and $\mathrm{Zn}$ ions in aqueous solution. Colloids Surf. A Physicochem. Eng. Asp. 2017, 533, 330-337. [CrossRef]

18. Zhang, T.; Zhu, X.; Shi, L.; Li, J.; Li, S.; Lü, J.; Li, Y. Efficient removal of lead from solution by celery-derived biochars rich in alkaline minerals. Bioresour. Technol. 2017, 235, 185-192. [CrossRef]

19. Xu, X.; Zhao, Y.; Sima, J.; Zhao, L.; Mašek, O.; Cao, X. Indispensable role of biochar-inherent mineral constituents in its environmental applications: A review. Bioresour. Technol. 2017, 241, 887-899. [CrossRef]

20. Zhang, W.; Du, W.; Wang, F.; Xu, H.; Zhao, T.; Zhang, H.; Ding, Y.; Zhu, W. Comparative study on Pb2+ removal from aqueous solutions using biochars derived from cow manure and its vermicompost. Sci. Total Environ. 2020, 716, 137108. [CrossRef]

21. Cui, X.; Fang, S.; Yao, Y.; Li, T.; Ni, Q.; Yang, X.; He, Z. Potential mechanisms of cadmium removal from aqueous solution by Canna indica derived biochar. Sci. Total Environ. 2016, 562, 517-525. [CrossRef] [PubMed]

22. Chang, J.; Zhang, H.; Cheng, H.; Yan, Y.; Chang, M.; Cao, Y.; Huang, F.; Zhang, G.; Yan, M. Spent Ganoderma lucidum substrate derived biochar as a new bio-adsorbent for $\mathrm{Pb}^{2+} / \mathrm{Cd}^{2+}$ removal in water. Chemosphere 2020, 241, 125121. [CrossRef] [PubMed]

23. Wang, J.; Wang, S. Preparation, modification and environmental application of biochar: A review. J. Clean. Prod. 2019, 227, 1002-1022. [CrossRef]

24. Zhao, B.; O'Connor, D.; Zhang, J.; Peng, T.; Shen, Z.; Tsang, D.C.W.; Hou, D. Effect of pyrolysis temperature, heating rate, and residence time on rapeseed stem derived biochar. J. Clean. Prod. 2018, 174, 977-987. [CrossRef]

25. Cao, Y.; Shen, G.; Zhang, Y.; Gao, C.; Li, Y.; Zhang, P.; Xiao, W.; Han, L. Impacts of carbonization temperature on the Pb(II) adsorption by wheat straw-derived biochar and related mechanism. Sci. Total Environ. 2019, 692, 479-489. [CrossRef] [PubMed]

26. Wei, J.; Tu, C.; Yuan, G.; Liu, Y.; Bi, D.; Xiao, L.; Lu, J.; Theng, B.K.G.; Wang, H.; Zhang, L.; et al. Assessing the effect of pyrolysis temperature on the molecular properties and copper sorption capacity of a halophyte biochar. Environ. Pollut. 2019, 251, 56-65. [CrossRef]

27. Li, S.; Chen, G. Thermogravimetric, thermochemical, and infrared spectral characterization of feedstocks and biochar derived at different pyrolysis temperatures. Waste Manag. 2018, 78, 198-207. [CrossRef] 
28. Chen, T.; Zhang, Y.; Wang, H.; Lu, W.; Zhou, Z.; Zhang, Y.; Ren, L. Influence of pyrolysis temperature on characteristics and heavy metal adsorptive performance of biochar derived from municipal sewage sludge. Bioresour. Technol. 2014, 164, 47-54. [CrossRef]

29. Zhang, J.; Wang, Q. Sustainable mechanisms of biochar derived from brewers' spent grain and sewage sludge for ammonianitrogen capture. J. Clean. Prod. 2016, 112, 3927-3934. [CrossRef]

30. Shen, Z.; Zhang, Y.; Jin, F.; McMillan, O.; Al-Tabbaa, A. Qualitative and quantitative characterisation of adsorption mechanisms of lead on four biochars. Sci. Total Environ. 2017, 609, 1401-1410. [CrossRef]

31. Park, J.-H.; Wang, J.J.; Kim, S.-H.; Kang, S.-W.; Jeong, C.Y.; Jeon, J.-R.; Park, K.H.; Cho, J.-S.; Delaune, R.D.; Seo, D.-C. Cadmium adsorption characteristics of biochars derived using various pine tree residues and pyrolysis temperatures. J. Colloid Interface Sci. 2019, 553, 298-307. [CrossRef] [PubMed]

32. Pariyar, P.; Kumari, K.; Jain, M.K.; Jadhao, P.S. Evaluation of change in biochar properties derived from different feedstock and pyrolysis temperature for environmental and agricultural application. Sci. Total Environ. 2020, 713, 136433. [CrossRef] [PubMed]

33. Shi, J.; Fan, X.; Tsang, D.C.W.; Wang, F.; Shen, Z.; Hou, D.; Alessi, D.S. Removal of lead by rice husk biochars produced at different temperatures and implications for their environmental utilizations. Chemosphere 2019, 235, 825-831. [CrossRef] [PubMed]

34. Shen, Z.; Hou, D.; Jin, F.; Shi, J.; Fan, X.; Tsang, D.C.W.; Alessi, D.S. Effect of production temperature on lead removal mechanisms by rice straw biochars. Sci. Total Environ. 2019, 655, 751-758. [CrossRef] [PubMed]

35. Agrafioti, E.; Bouras, G.; Kalderis, D.; Diamadopoulos, E. Biochar production by sewage sludge pyrolysis. J. Anal. Appl. Pyrolysis 2013, 101, 72-78. [CrossRef]

36. Li, H.; Dong, X.; da Silva, E.B.; de Oliveira, L.M.; Chen, Y.; Ma, L.Q. Mechanisms of metal sorption by biochars: Biochar characteristics and modifications. Chemosphere 2017, 178, 466-478. [CrossRef]

37. Elaigwu, S.E.; Rocher, V.; Kyriakou, G.; Greenway, G.M. Removal of $\mathrm{Pb}^{2+}$ and $\mathrm{Cd}^{2+}$ from aqueous solution using chars from pyrolysis and microwave-assisted hydrothermal carbonization of Prosopis africana shell. J. Ind. Eng. Chem. 2014, 20, 3467-3473. [CrossRef]

38. Chen, G.; Wang, C.; Tian, J.; Liu, J.; Ma, Q.; Liu, B.; Li, X. Investigation on cadmium ions removal from water by different raw materials-derived biochars. J. Water Process Eng. 2020, 35, 101223. [CrossRef]

39. Wang, R.-Z.; Huang, D.-L.; Liu, Y.-G.; Zhang, C.; Lai, C.; Zeng, G.-M.; Cheng, M.; Gong, X.-M.; Wan, J.; Luo, H. Investigating the adsorption behavior and the relative distribution of $\mathrm{Cd}^{2+}$ sorption mechanisms on biochars by different feedstock. Bioresour. Technol. 2018, 261, 265-271. [CrossRef]

40. Lu, H.; Zhang, W.; Yang, Y.; Huang, X.; Wang, S.; Qiu, R. Relative distribution of $\mathrm{Pb}^{2+}$ sorption mechanisms by sludge-derived biochar. Water Res. 2012, 46, 854-862. [CrossRef]

41. Wang, Z.; Liu, G.; Zheng, H.; Li, F.; Ngo, H.H.; Guo, W.; Liu, C.; Chen, L.; Xing, B. Investigating the mechanisms of biochar's removal of lead from solution. Bioresour. Technol. 2015, 177, 308-317. [CrossRef] [PubMed]

42. Zheng, H.; Wang, Z.; Deng, X.; Zhao, J.; Luo, Y.; Novak, J.; Herbert, S.; Xing, B. Characteristics and nutrient values of biochars produced from giant reed at different temperatures. Bioresour. Technol. 2013, 130, 463-471. [CrossRef] [PubMed]

43. Lagergren, S. Zur theorie der sogenannten adsorption geloster stoffe Kungliga Svenska Vetenskapsakademiens. Handlingar 1898, 24, 1-39.

44. Blanchard, G.; Maunaye, M.; Martin, G. Removal of heavy metals from waters by means of natural zeolites. Water Res. 1984, 18, 1501-1507. [CrossRef]

45. Inglezakis, V.J.; Fyrillas, M.M.; Park, J. Variable diffusivity homogeneous surface diffusion model and analysis of merits and fallacies of simplified adsorption kinetics equations. J. Hazard. Mater. 2019, 367, 224-245. [CrossRef] [PubMed]

46. Foo, K.Y.; Hameed, B.H. Insights into the modeling of adsorption isotherm systems. Chem. Eng. J. 2010, 156, 2-10. [CrossRef]

47. Wang, X.; Li, X.; Liu, G.; He, Y.; Chen, C.; Liu, X.; Li, G.; Gu, Y.; Zhao, Y. Mixed heavy metal removal from wastewater by using discarded mushroom-stick biochar: Adsorption properties and mechanisms. Environ. Sci. Process. Impacts 2019, 21, 584-592. [CrossRef]

48. Duan, C.; Ma, T.; Wang, J.; Zhou, Y. Removal of heavy metals from aqueous solution using carbon-based adsorbents: A review. J. Water Process Eng. 2020, 37, 101339. [CrossRef]

49. Liu, Z.; Niu, W.; Chu, H.; Zhou, T.; Niu, Z. Effect of the Carbonization Temperature on the Properties of Biochar Produced from the Pyrolysis of Crop Residues. Bioresources 2018, 13, 3439-3446. [CrossRef]

50. Jindo, K.; Mizumoto, H.; Sawada, Y.; Sánchez-Monedero, M.Á.; Sonoki, T. Physical and chemical characterization of biochars derived from different agricultural residues. Biogeosciences 2014, 11, 6613-6621. [CrossRef]

51. Xu, Q.; Tang, S.; Wang, J.; Ko, J.H. Pyrolysis kinetics of sewage sludge and its biochar characteristics. Process Saf. Environ. Prot. 2018, 115, 49-56. [CrossRef]

52. Yuan, J.-H.; Xu, R.-K.; Zhang, H. The forms of alkalis in the biochar produced from crop residues at different temperatures. Bioresour. Technol. 2011, 102, 3488-3497. [CrossRef] [PubMed] 